\title{
Recent evolution of spatial and temporal patterns of burnt areas and fire weather risk in the Iberian Peninsula
}

T. Calheiros (1), J.P. Nunes (1), M.G. Pereira (2,3)

(1) CE3C - Centre for Ecology, Evolution and Environmental Changes, Faculdade de Ciências, Universidade de Lisboa, 1749-016 Lisboa, Portugal

(2) Centro de Investigação e de Tecnologias Agro-Ambientais e Biológicas (CITAB), Universidade de Trás-os-Montes e Alto Douro, Vila Real, Portugal

(3) Instituto Dom Luiz (IDL), Universidade de Lisboa, Lisboa, Portugal

Version of Agricultural and Forest Meteorology, Volume 287, 15 June 2020, 107923

Accepted 29 January 2020

https://doi.org/10.1016/j.agrformet.2020.107923

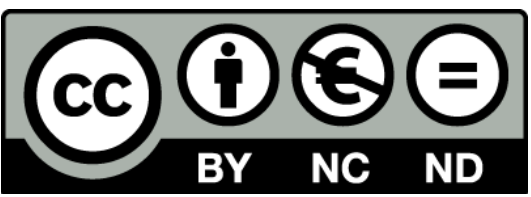

(C) 2020. This manuscript version is made available under the CC-BY-NC-ND 4.0 license http://creativecommons.org/licenses/by-nc-nd/4.0/ 


\section{ABSTRACT}

The weather is an important driver of the wildfire incidence because it strongly influences fuel availability and flammability. In the Mediterranean climate, the spatial and temporal patterns of fire weather present high variability, which help to understand the variable fire regimes. To assess this link in the Iberian Peninsula and the role of fire weather on fire incidence variability, this work identified pyro-regions, characterized the fire regimes in these regions and compared them with the spatial and seasonal distribution of several components of the Canadian Forest Fire Weather Index (FWI) System. A cluster analysis was performed on monthly normalized burnt area (NBA) series for the 1980 - 2015 period in each administrative division of the Iberian Peninsula (Portuguese districts and Spanish provinces), which revealed four pyro-regions (Northwest, North, Southwest and East) as well as significant spatial and temporal variability of NBA patterns. A separate analysis for 1980 - 1997 and 1998 - 2015 revealed noteworthy changes in the border of pyro-regions caused by changes in NBA seasonal patterns in some administrative regions. The analysis of the fire weather risk distribution for $1980-2017$ included the assessment of extreme fire weather days, defined as days with Daily Severity Rating (DSR) above the $95^{\text {th }}$ percentile, for the summer fire season, and as days with Drought Code above the $95^{\text {th }}$ percentile, for the winter-spring fire season. The distribution of the monthly extreme fire weather days is highly correlated with the NBA seasonal variability and explains the differences between seasonal wildfire characteristics and the recent changes in the border administrative regions. The analysis of the fire weather patterns for large wildfires disclosed that these events were linked with extreme DSR days, especially in the NW pyro-region. These findings highlight the strong link between climate variability and fire regimes in the Iberian Peninsula, and can therefore help assess the impacts of climate change and to project future burnt area patterns. 


\section{KEYWORDS}

Wildfires, Fire weather risk, Pyro-regions, Cluster analysis, Iberian Peninsula 


\section{Introduction}

Wildfires cause severe damage and fatalities every year around the world, and most of the consequences, particularly injuries and deaths, are caused by large/extreme wildfires. In 2017, the Iberian Peninsula (hereafter Iberia) was highly affected by large wildfires, which caused 121 fatalities and burned 718000 ha (San-miguel-ayanz et al., 2018). Large wildfires have also occurred recently in other regions with a Mediterranean type of climate, such as in California (USA), Greece, and Chile in 2017 and 2018 (Barrera et al., 2018), also leading to fatalities and property damage. Large fires are just one component of the fire regime but are also able to change other aspects such as the fire incidence space time patterns, frequency, seasonality or severity, among others (Gill and Allan, 2008). Therefore, mitigating and managing fire damage requires a deep understanding of fire regimes, and especially of the occurrence of large wildfires, their spatial distribution, and potential changes in the future.

In addition to landscape characteristics and human factors, weather conditions (especially precipitation, wind, air temperature and humidity) and climate variability (at monthly and longer time scales) have a very strong influence on fuel availability, flammability, fire spread, and, therefore, play an important role on wildfire activity and incidence (Telesca and Pereira, 2010; Flannigan et al., 2013; Pereira et al., 2013; Hernandez et al., 2015; Sousa et al., 2015; Parks et al., 2016; Trigo et al., 2016). In regions of transition between wet and dry climate, fire weather patterns have high spatial and temporal variability (Venevsky et al., 2018). It is therefore important to characterise the links between weather conditions and current fire regimes, to understand how changes in the former might affect the latter.

Fire weather risk is usually assessed with fire weather indices. The Canadian Forest Fire Weather Index System (CFFWIS) (van Wagner and Pickett, 1985; Van Wagner, 1987), has been used to model current and future fire activity, as well as to help forest and fire managers as well as national authorities in prevention and suppression activities all over the world (Li et 
al., 2008; Wotton, 2009; Flannigan et al., 2013, 2016) and, especially, in the Mediterranean (Amatulli et al., 2013; Pereira et al., 2013; Bedia et al., 2014). More recently, Jimenez-Ruano et al. (2018) studied several fire weather danger rating indices, including the Fire Weather Index (FWI), concluding that these indices could provide useful information about upcoming fire activity up to two months ahead of time, and that they could explain seasonal variability but not necessarily ongoing trends. On the other hand, Pérez-Sánchez et al. (2017) showed that the FWI is the most suitable index for semiarid regions, such as SE Iberia. While global burned area appears to have declined in recent decades (Doerr and Santín, 2016), it is possible that recent climate change has already affected fire weather and fire incidence in some regions (Abatzoglou and Williams, 2016).

The Mediterranean part of Iberia can be a good example of recent changes in other Mediterranean regions due to the high fire incidence (Rasilla et al., 2010; Sousa et al., 2015; Trigo et al., 2016; Rodrigues et al., 2019). Wildfire activity is not the result of a random process, neither in time nor in space, and several factors (weather, climate, human, and landscape factors) contribute for the existence of time, space, and space-time wildfire clusters (Parente et al. 2016). Different methods have been developed, tested and used to detect clustering patterns in fire incidence (Pereira et al., 2015; Tonini et al., 2016; Kanevski and Pereira, 2017). Several studies developed zoning approaches with the purpose of identifying regions with similar fire regime, using different fire data analysis, such as burnt area tendency (Silva et al., 2019), intraannual pattern of burnt area (Sousa et al., 2015; Trigo et al., 2016), fire activity and fire weather risk (Jimenez-Ruano et al., 2018) or other variables that affect fire (Moreno and Chuvieco, 2013). These studies show that the analysis of existing burnt area and meteorological data for the last few decades can help to detect the impacts of recent climate changes on fire weather danger and risk and, perhaps more importantly, on fire regimes. 
The main objective of this work was therefore to identify and characterise pyro-regions in Iberia in two 18 year time periods: 1980-1997 and 1998-2015, and to identify and analyse recent changes in these regions due to changing weather and fire regime. The second objective was to study the fire regime in each pyro-region using fire weather indices, assess the role of extreme fire weather, and analyse the role played by the recent evolution of extreme weather patterns in changes to the borders of pyro-regions. Finally, the third objective was to go beyond these studies and assess the capacity of fire weather risk indices to predict the occurrence of major fires in Iberia in recent years. A Summary Figure regarding the framework of this manuscript is in Appendix A.

\section{Materials and methods}

\subsection{Wildfire regime in the Iberian Peninsula}

In Europe, wildfires have higher incidence and consequences in the Mediterranean region (Batllori et al., 2013; Camara et al., 2014). The analysis of the fire incidence in Europe reveals that the southern European countries (Portugal, Spain, France, Italy and Greece) were the most affected in the 1980 - 2017 period. The Iberian countries (Portugal and Spain) account for 68\% of the total number of fires (NF) and $60 \%$ of total burnt area (BA) and these wildfires caused extensive and diverse damage (Cardil and Molina, 2015; San-miguel-ayanz et al., 2018; Molina-Terrén et al., 2019).

The fire regime in Iberia is particularly sensitive to weather and climate variability. High fire incidence is associated to anomalous atmospheric circulation and thermodynamic patterns (Pereira et al., 2005; Trigo et al., 2006; Hoinka et al., 2009; Rasilla et al., 2010; García-Ortega et al., 2011; Amraoui et al., 2015) as well as extreme events such as heatwaves and droughts (Russo et al., 2017; J. Parente et al., 2018; Parente et al., 2019). Spatial and temporal patterns of fire incidence are linked with fire weather types, with distinct patterns for different regions 
(Rasilla et al., 2010; Trigo et al., 2016), and fire weather parameters have been shown to be good predictors of burnt area (Pereira et al., 2013; Sousa et al., 2015).

There is an extensive body of literature on the characteristics and factors of the fire regime in Iberia. In Portugal, the spatial and temporal distribution of wildfires presents clustering patterns (Telesca and Pereira, 2010; Pereira et al., 2015; Parente et al., 2016; Tonini et al., 2016; Kanevski and Pereira, 2017). The temporal pattern of both metrics of fire incidence (number of wildfires and burnt area) is characterised by a main summer fire season and a secondary spring peak, both driven by the type of climate and climate variability, especially the occurrence of extreme weather and climate conditions (Pereira et al., 2005; Trigo et al., 2006; Amraoui et al., 2015). The spatial pattern reveals two different fire regimes, at north and south of the Tagus River (respectively the western and southwestern regions of Iberia), associated to human and other biophysical drivers, including weather and climate (Pereira et al., 2015; Parente et al., 2016). Those drivers form the basis for mapping susceptibility and structural fire risk (Parente and Pereira, 2016; Leuenberger et al., 2018).

The influence of weather and climate variability is particularly significant for large/extreme wildfires. The largest wildfires in western Iberia tend to occur during drought periods and heatwaves, associated with easterly or southerly winds, characterized by a very hot and dry air mass advected from northern Africa (Pereira et al., 2005; Amraoui et al., 2015; J. Parente et al., 2018; Parente et al., 2019; Rodrigues et al., 2019).

In Spain, there is a strong evidence that the magnitude of wildfire risk conditions is influenced by atmospheric circulation patterns, showing substantial regional differences, while a combination of short and long term climate variability is needed to explain episodes of very large wildfires (Rasilla et al., 2010). A recent work (Rodrigues et al., 2019) showed that wildfires have different explanatory factors in each region: (i) in the northwest region, wildfires are mostly caused by eastern wind during summer and southern wind during winter; (ii) in the 
northern Mediterranean coast (Catalonia), wildfires are promoted by northerly winds; (iii) in the southern regions (Andalucía), wildfires are linked to cyclonic or south-eastern wind and extreme heat episodes during summer; and, (iv) in mountainous areas, wildfires are related to adiabatic heating of the air flow. In north-eastern Iberia, enhanced firefighting capability has reduced the number of wildfires and fire sizes in mild and dry years, but wildfires occurring in wind-dominated situations are still the most difficult to control and have not diminished over time (Duane and Brotons, 2018). Other recent studies showed that the number of wildfires in NE Spain during the $1970-2007$ period presents a negative trend, combined with an also slightly negative trend in burnt area (Turco et al., 2014).

\subsection{Fire Weather Index and Meteorological Data}

The Fire Weather Index (FWI) and Daily Severity Rating (DSR) are two widely used components of the CFFWIS (van Wagner and Pickett, 1985; Van Wagner, 1987). The FWI rates fire intensity while the DSR evaluates the difficulty to control wildfires. The basic structure of FWI (Van Wagner and Pickett, 1975; de Groot, 1987) is the following:

- FWI is the result of two other fire behaviour indices, the Initial Spread Index (ISI) and the Buildup Index (BUI):

- ISI is a numeric rating of the expected spread of fire and depends on the wind speed and of the Fine Fuel Moisture Code (FFMC), which is an indicator of the relative easiness of ignition and the flammability of fine fuel and computed with rainfall, wind speed, air temperature and relative humidity (Van Wagner, 1987);

- BUI rates the total amount of fuel available for combustion by combining two fuel moisture codes: the Duff Moisture Code (DMC), which depends of temperature, relative humidity and rainfall, and provides an indication of fuel consumption; and, the Drought Code (DC), which is a numeric rating of the 
average moisture content of deep, compact organic layers, and an useful indicator of seasonal drought effects, computed with air temperature and rainfall.

- ISI and BUI are computed with 3 fuel moisture codes, which aim to numerically rate the moisture content of different layers of forest floor fuels, in a "standard" mature pine stand;

- ISI is computed with wind and Fine Fuel Moisture Code (FFMC);

- FFMC refers to the thin (1-2 cm deep) surface layer of litter and other cured fine fuels with the lowest fuel load; FFMC change rapidly and only have a short-term memory (3 days);

- BUI results from the Duff Moisture Code (DMC) and Drought Code (DC):

- DMC, represents moderate depth duff layer $(5-10 \mathrm{~cm})$ of loosely-compacted organic layers, with average fuel load and a drying rate time lag of 12 days;

- DC indicate the moisture content of deep $(10-20 \mathrm{~cm})$ compact organic layer, with the highest fuel load, only affected by significant rainfall and very slow drying rate (time lab of 52 days).

The DSR, FWI and all its components were calculated for the $1980-2017$ period using the Van Wagner and Pickett, 1975 equations and program as well as daily values at $12 \mathrm{~h} 00$ of air temperature (at 2 meters), relative humidity (at 2 meters), wind speed (at 10 meters, including the meridional and zonal components), and 24 hour accumulated total precipitation. Relative humidity was calculated from dew point temperature and temperature at noon using the Magnus Formula (Alduchov and Eskridge, 1996). These meteorological data were extracted from the ERA-Interim reanalysis dataset provided by the European Centre for Medium-Range Weather Forecasts (Dee et al., 2011). While the new ERA5 dataset was not available at the time of this calculation, the improvements on temporal resolution and other processes are not particularly 
relevant for this study. ERA-Interim data are regularly updated since 1979 and it is currently based on an assimilation data system, with a temporal resolution of 12 hours (Berrisford et al., 2009; Dee et al., 2011). The spatial resolution of the data set is approximately $80 \mathrm{~km}$ (T255 spectral) on 60 vertical levels from the surface up to $0.1 \mathrm{hPa}$; However, data are also provided at $0.125^{\circ} \times 0.125^{\circ}$ resolution, based on a bilinear interpolation technique for continuous parameters (Liu et al., 2018).

The analysis focused on the main indices: DSR, as well as ISI, BUI and DC, since (de Groot, 1987):

- DSR is one of the most used indices, and the FWI is frequently used to inform the general public about fire weather danger conditions;

- ISI already reflects the influence of FFMC while BUI already reflects the influence of DMC, but not so much of DC;

- FFMC and DMC relate with processes with shorter time scales than that of this study, as FFMC has a short-term memory of weather conditions and DMC fuels have much shorter drying rates;

- FFMC and DMC are proxies of, respectively, the ease of ignition/ignition probability and of the probability of lightning fire start, but in Iberia high fire incidence occurs after long dry periods and natural/lightning wildfires are extremely rare (Parente et al., 2018; Rodrigues et al., 2018).

A more in-depth analysis of FFMC and DMC supporting the selection of the fire weather indices used in this study is provided in Appendix B.

\subsection{Fire Data}

The Normalized Burnt Area (NBA) was computed for each month of the $1980-2015$ period and for each administrative region of Iberia: 18 Portuguese districts and 48 Spanish provinces. 
Only the Spanish provinces and islands correspond to the NUTS3 administrative division. NBA is equal to the monthly burnt area divided by the area of the district/province, presented in permillage (\%), and this normalization process allows the proper comparison of burnt areas between administrative regions with different areas. When compared with dividing the burnt area by the forested or vegetated area of each region, this normalization procedure has the advantage of allowing a comparison of the results with those of previous studies (Sousa et al., 2015; Trigo et al., 2016).

Wildfire data for Spain were obtained from the Dirección General de Medio Natural y Politica Forestal (ADCIF, 2018) and for Portugal were provided by the national Institute for the Conservation of Nature and Forests (Instituto da Conservação da Natureza e das Florestas, ICNF) (ICNF, 2018). The period for which homogeneous wildfire data are available $(1980-2015)$ is slightly less than the period covered by the weather data $(1980-2017)$. Both datasets comprise detailed information on burnt area (by land cover type), duration of fire (date of ignition and extinction) and location (district/province, municipality and parish/local name) and have been widely used in many and recent wildfire studies (Pereira et al., 2011; Sousa et al., 2015; Trigo et al., 2016; Rodrigues et al., 2019). We selected this level of aggregation to provide comparable results with previous studies; this resolution is appropriate for an analysis at the scale of the Iberia and provides information at the level at which landscape management is usually performed.

Following the procedures adopted by Trigo et al. (2016), missing data for the Spanish provinces of Álava (for 1980 - 1984), and Navarra (1980 - 1984 and 1994 -2002) were corrected with the long-term monthly mean NBA values for the 1980 - 2005 period. This correction had a very limited impact, as these regions have mean annual burnt area below $0.5 \%$ of the total province area in Álava and below $0.1 \%$ in Navarra (Trigo et al., 2016). The method of counting the number of wildfires in Portugal changed considerably in beginning of the 1990's, affecting the 
dataset completeness (Pereira et al., 2011). Additionally, Jiménez-Ruano(2017) reveals that the fires smaller than 1 ha were not fully compiled in the Spanish database until 1988. Therefore, to unify and homogenize the datasets, only fires with burnt area greater or equal to 0.1 ha were used in this study. However, the removal of these small fires has a very small influence $(0.3 \%$ of burnt area in 1980 -2005) in the monthly and annual total burnt area in Portugal (Pereira et $a l ., 2011)$, so the effects in Spain are probably also small.

\subsection{Cluster Analysis}

For comparison purposes, a cluster analysis of the NBA spatial distribution was performed using the k-means clustering algorithm, previously used for a similar purpose by Trigo et al. (2016) and Sousa et al. (2015). In this study, cluster analysis is used to detect if the pyro-regions remain "stable" i.e., if they include the same districts/provinces, which will detect if any administrative region changed the NBA variability pattern. This algorithm was applied to the monthly NBA of the 66 administrative divisions, arranged in a T-mode correlation matrix, using correlation as the distance measure, and tested with 4 and 5 clusters. However, tests with 5 clusters did not provide easily interpretable results. Data from the insular Baleares province were also used in this analysis for comparison purposes but were not included in subsequent work. The purposes of this procedure are to identify the provinces with the same seasonal NBA pattern, distribute the provinces by the 4 pyro-regions previously identified for $1980-2005$ by (Trigo et al.,2016; Sousa et al.,2015). The analysis was conducted independently for two subsequent periods, $1980-1997$ and $1998-2015$, as well as for the entire study period $(1980-2015)$, to explore potential changes in the spatial and temporal patterns of fire distribution and fire regimes in recent decades. The selection of these two periods seemed to be the most straightforward given the available data, but there are some indications of significant changes in the fire regime in some years of both studies and countries (Parente et al., 2016; Jiménez-Ruano et al., 2017). A possible bias in spatial clustering should be mentioned as a 
consequence of the spatial smoothing of the ERA data, meaning that a cluster analysis based on weather station data might lead to results with lower spatial coherence.

\subsection{Extreme days}

In this work, extreme days were defined as:

(i) days when DSR was greater than the monthly $95^{\text {th }}$ percentile for the summer/hot fire season/semester (May to October), i.e. the months where cumulated fraction of NBA reaches $90 \%$ of the total;

(ii) days when DC was greater than the monthly $95^{\text {th }}$ percentile, for the winter/cold fire season/semester (November to April).

This definition aimed to assess the link of the NBA seasonal variability with extreme fire weather in each pyro-region. The dual approach between summer and winter was chosen due to the Mediterranean type of climate of Iberia (Kottek et al., 2006; Rubel et al., 2017). This temperate type of climate is characterized by wet and mild winters/springs, which promote the development of vegetation; and by hot and dry summers, which promote the hydrological and thermal stress of the vegetation (Pereira et al., 2013). This type of climate is the main responsible for the high seasonality of the temporal distribution of the fire incidence metrics with much higher values during the summer months of July, August and September (Telesca and Pereira, 2010).

Since the peninsula's vegetation is adapted to these conditions, high fire incidence is mainly promoted by extreme weather (heat waves) and climatic (drought) conditions (J. Parente et al., 2018; Parente et al., 2019). As pointed out by Amraoui et al. (2015) extreme fire activity in Iberia during summer and winter is associated with relatively different anomalous weather conditions, respectively abnormally high values of air temperature and low values of humidity. Therefore, DSR was used to identify extreme days during the summer/hot season/semester, as 
it accounts for both air temperature and humidity; while DC was used to identify extreme days during the winter/cold fire season/semester, as it rates drought conditions in the lower layer of the soil and better accounts for prolonged drought. In summary, DC is more suitable than DSR for spring and winter months because most of burnt area in spring and winter is associated to dry conditions and air temperature is relatively low. The winter season analysis focused on March, due to both the relatively high number of fires and burnt area in this month, especially in the $\mathrm{N}$ pyro-region, and since it also has a high number of ignitions due to agricultural practices. DC anomalies in this month were also computed for each pyro-region, using the spatial average for the period 1980 - 2015, to assess the link between DC and NBA/number of fires.

Although the $90^{\text {th }}$ percentile is usually defined as an extreme day threshold (Bedia et al., 2012; Tsinko et al., 2018), the $95^{\text {th }}$ percentile was chosen because it is more suitable to detect extreme values in relatively long period of analysis. It was computed using data of the same month for the same period of NBA data $(1980-2015)$. Although fire incidence is concentrated from February to May and from June to October, the extreme days were set for each month to check the temporal distribution of the extreme days throughout the year. The extreme day definition is particularly suitable to identify summer extreme days (Bedia et al., 2012), since relevant meteorological variables, fire weather indices and NBA present high seasonal variability with a (major) peak during summer. The comparison with monthly percentiles and the differentiation between the hot and cold seasons/semesters aimed to remove (at least partially) the typical seasonal cycle of precipitation and air temperature in Mediterranean climates, since low extremes of precipitation in the cold season can be considered normal during summer months. 


\section{Results and Discussion}

\subsection{Burnt area and pyro-regions}

The cluster analysis for 1980 - 2015 revealed the same pyro-regions identified by Sousa et al. (2015) and Trigo et al. (2016) for 1980 - 2005 (Table 1 and Figure 1). These are the Northwest $(\mathrm{NW})$, North (N), East (E) and Southwest (SW) pyro-regions, which present different seasonal distributions of NBA. However, the cluster analysis for 1980-1997 and $1998-2015$ subperiods differed in five frontier provinces which changed their pyro-region (Figure 1).

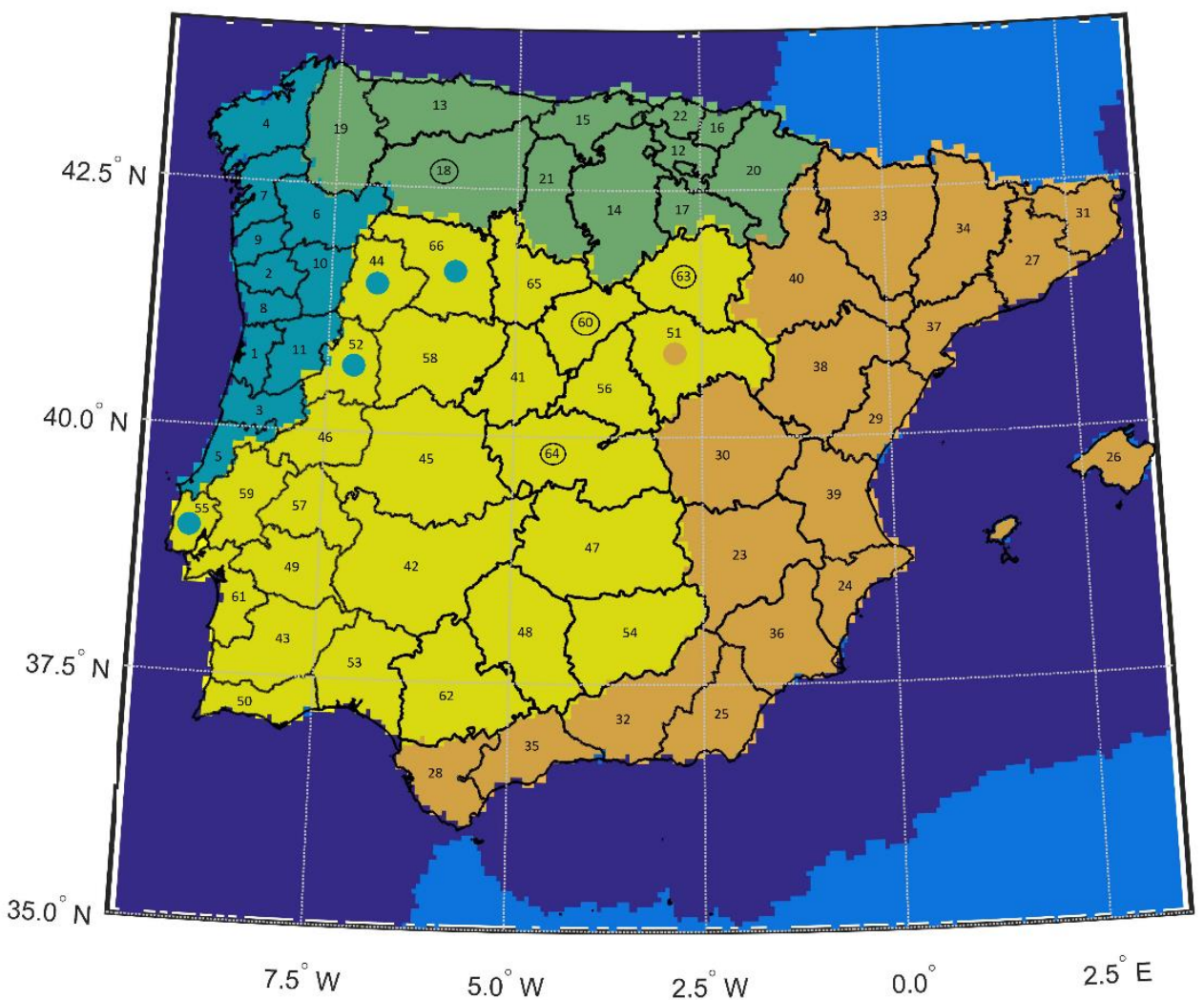

Figure 1: Pyro-regions identified for the 1980 - 2015 period: NW (blue), N (green), SW (yellow) and E (orange). The blue circles identify administrative divisions that change from the SW to the NW pyro-region from 1980 - 1997 to 1998 - 2015. The orange circle represents a province that changes from the SW to the E pyroregion between 1980 - 1997 and 1998 - 2015. The black circle around the number identify the provinces where 
observed seasonal distribution did not completely correspond to the algorithm result. The numbers identify the administrative regions listed in Table 1.

Table 1: Composition of the pyro-regions identified for the period 1980 - 2015 in the Iberian Peninsula, showing the number and name of the administrative regions (Portuguese districts and Spanish provinces) which integrate each pyro-region. Underlined administrative regions are those who changed their pyro-region, when analysing the two sub-periods (1980-1997 and 1998-2015).

\begin{tabular}{|c|c|}
\hline Pyro-regions & Portuguese Districts/Spanish Provinces \\
\hline Northwest (NW) & $\begin{array}{l}\text { Aveiro (1), Braga (2), Coimbra (3), La Coruña (4), Leiria (5), Orense } \\
\text { (6), Pontevedra (7), Porto (8), Viana do Castelo (9), Vila Real (10) and } \\
\text { Viseu (11). }\end{array}$ \\
\hline North $(\mathrm{N})$ & $\begin{array}{l}\text { Álava (12), Asturias (13), Burgos (14), Cantabria (15), Guipúzcoa (16), } \\
\text { La Rioja (17), Leon (18), Lugo (19), Navarra (20), Palencia (21) and } \\
\text { Vizcaya (22). }\end{array}$ \\
\hline East (E) & $\begin{array}{l}\text { Albacete (23), Alicante (24), Almeria (25), Baleares (26), Barcelona } \\
\text { (27), Cádiz (28), Castellón (29), Cuenca (30), Gerona (31), Granada } \\
\text { (32), Huesca (33), Lérida (34), Málaga (35), Murcia (36), Tarragona } \\
\text { (37), Teruel (38), Valencia (39), Zaragoza (40). }\end{array}$ \\
\hline Southwest (SW) & $\begin{array}{l}\text { Ávila (41), Badajoz (42), Beja (43), Bragança (44), Cáceres (45), } \\
\text { Castelo Branco (46), Ciudad Real (47), Córdoba (48), Évora (49), Faro } \\
\text { (50), Guadalajara (51), Guarda (52), Huelva (53), Jaén (54), Lisboa (55), } \\
\text { Madrid (56), Portalegre (57), Salamanca (58), Santarém (59), Segovia } \\
\text { (60), Setúbal (61), Sevilla (62), Soria (63), Toledo (64), Valladollid (65) } \\
\text { and Zamora (66). }\end{array}$ \\
\hline
\end{tabular}


The NW pyro-region covers the western provinces of Galicia in Spain and the north-western part of Portugal and has the highest NBA values. The N pyro-region covers the extreme north of Spain and is characterized by the lowest NBA values in summer and the second highest in winter months. The E pyro-region includes the Mediterranean region of the Peninsula, extends from the eastern Pyrenees to Gibraltar, and has the third highest NBA values. The SW pyroregion covers a large area of the south-western and central Peninsula, having the second highest NBA values in summer. In the provinces of Léon (18), Segovia (60), Soria (63) and Toledo (64), the observed seasonal distribution did not completely correspond to the algorithm output; some of these provinces were also "outside" the pyro-regions determined by Trigo et al. (2016). Overall, the seasonal variability of NBA in Iberia in $1980-2015$ is characterized by a prominent summer peak in the 4 pyro-regions, and secondary lower peak in March in the $\mathrm{N}$ and NW pyro-regions (Figure 2, top panel). The ratio between NBA in August and March is the main criteria separating the NW and SW pyro-region. However, significant differences to this general temporal pattern exist between different pyro-regions:

- In the NW, NBA has two peaks of fire incidence during the year: a relatively small one centred in March (monthly mean of NBA is $0.96 \%$ ) and a substantially higher one in August (8.47\%o); July and September also present high values of NBA $(>2.95 \%)$, which means that burnt area in the NW pyro-region occurs mostly in Summer. As for interannual variability, this is the pyro-region with the highest NBA values in a single year (the maximum is almost $4.0 \%$ ), pointing to the dominance of years with large fires, especially in August;

- NBA in the $\mathrm{N}$ pyro-region also presents two peaks, the first also centred in March $(0.79 \%)$ and the second in September $(0.72 \%)$, but the NBA is slightly higher in winter/spring than in summer. The high NBA in December is due to an outlier, i.e., a very high NBA in just one specific year; 

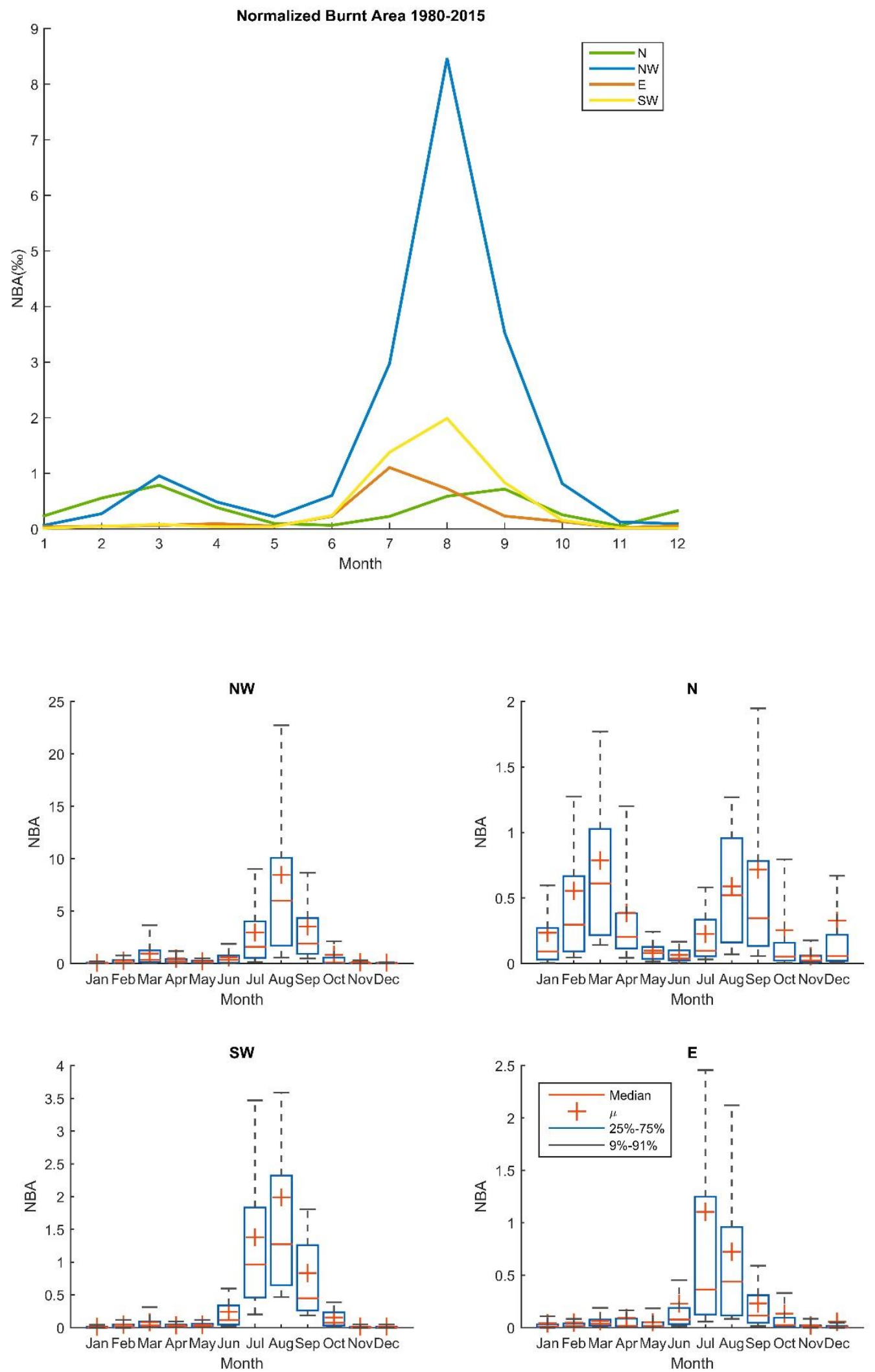

Figure 2: Monthly averages of the NBA (in permillage, \%o) (top panel); box-whisker plots of monthly NBA time series in each pyro-region (bottom panel) for the 1980 - 2015 period. 
- In the E pyro-region, the NBA has only one clear summer peak, with the highest values in July (1.10\%o) and August (0.72\%o);

- Finally, in the SW pyro-region, the NBA also has one peak in the summer months, especially in August (1.99\%), July (1.38\%o) and September (0.83\%o).

An uncertainty analysis was performed in each pyro-region to assess if the extreme values (in this case, values above the 97.5 percentile) can significantly affect the NBA long term average. The results (confidence intervals at 95\%) reveal that, in general, extreme values do not affect the intra-annual pattern in any of the four pyro-regions. However, the similarity between the two annual peaks in the $\mathrm{N}$ pyro-region can easily change by the occurrence of extreme wildfires with the ability to change the relatively low NBA in any of the two fire seasons.

An important distinction between the NW pyro-region and those of the rest of Iberia is that the NBA in winter months in the N and NW is higher (more than the double) than in the $\mathrm{W}$ and $\mathrm{E}$. Another relevant distinction, this time between the east and west halves of Iberia, is that NBA in the summer months is higher in the NW and SW than in the $\mathrm{N}$ and $\mathrm{E}$ pyro-regions. The differences between the NW and SW are due to the NBA peak in March in the former.

The seasonal variability of the NBA in the five administrative regions that changed pyro-region from 1980 - 1997 to 1998 - 2015 (Figures 3a and 3b) was analysed in detail. In Guadalajara, the summer peak moved from August to July while the maximum NBA almost doubled (from $0.48 \%$ o to $0.88 \%$ ), conditions which classify it as a member of the E pyro-region. The other four regions (Bragança, Guarda, Lisboa and Zamora) changed from the SW to the NW pyroregion, mostly due to differences in the ratio between NBA in August and March, which is the main criteria separating these two regions: 
- In Bragança and Guarda, the pyro-region change was due to an NBA increase in March, accompanied by a lower NBA increase (Bragança) or no change (Guarda) in August. The ratio changed from 43 to 7 in Bragança and from 68 to 26 in Guarda.

- In Lisboa and Zamora, the pyro-region change followed a significant NBA decrease in August, together with little changes to the NBA in March. Ratio changed from 186 to 23 in Lisboa and from 5 to 2 in Zamora.

The $95 \%$ confidence intervals of average NBA were also computed to assess if the extreme values affect the results (Figure 3); the results show that extreme values do not compromise the intra annual pattern.
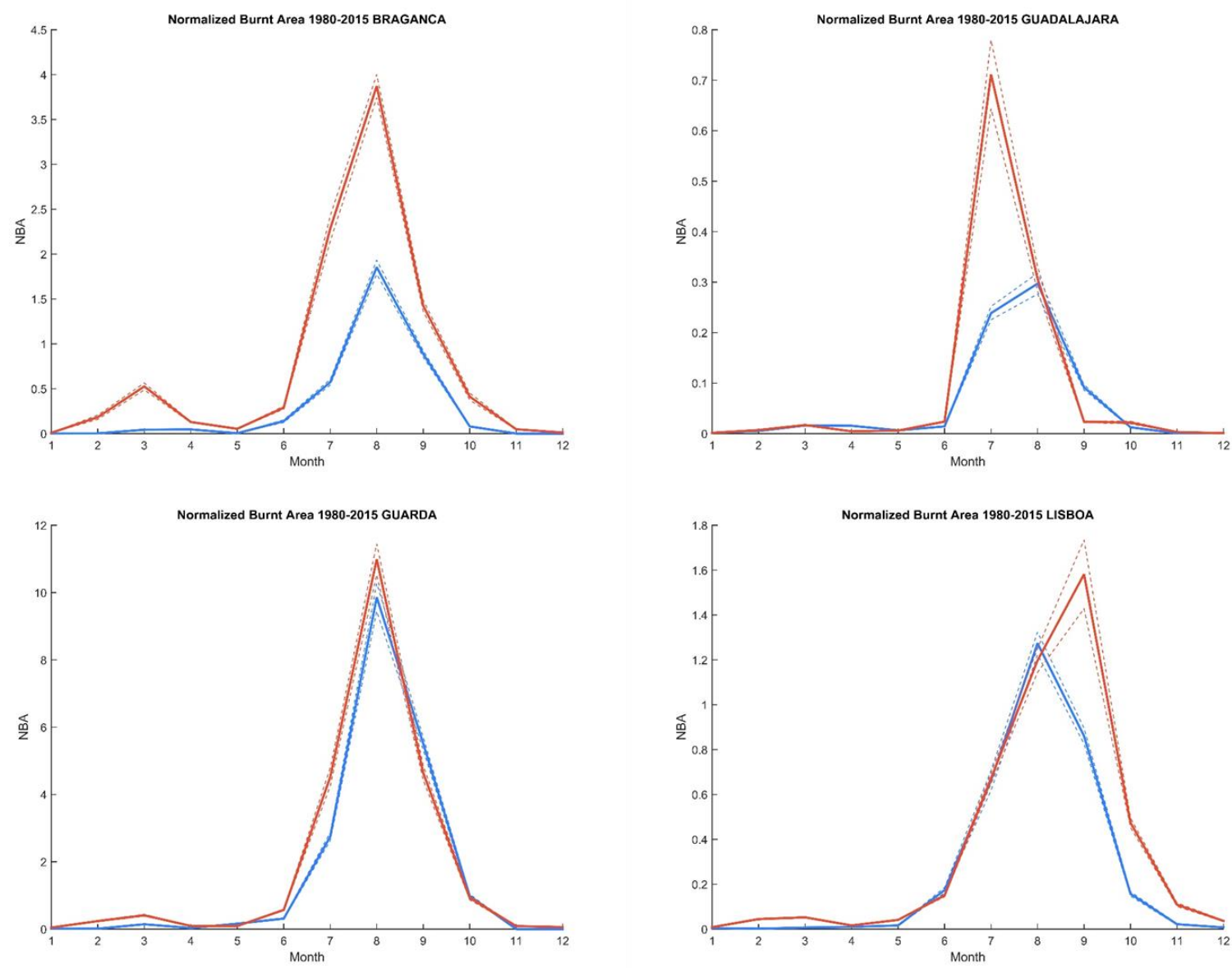

Figure 3a: Monthly averages of the NBA (in permillage, \%o) with 95\% confidence intervals for the $1980-1997$ and 1998 - 2015 in four administrative regions that changed pyro-region from the first to the second sub period. Solid lines describe the intra-annual variability; dashed lines define the $95 \%$ confidence intervals. 


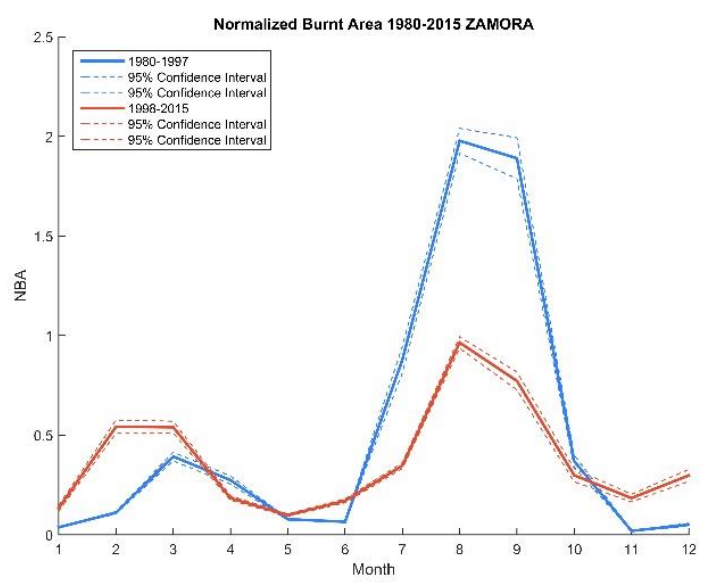

Figure 3b: Same as Figure 3a, but only for one administrative region.

The pyro-region arrangement shown in Figure 1 agrees well with the Köppen climatic classification of Iberia (Figure 4). According to Kottek et al. (2006) and Rubel et al. (2017) the Iberian Peninsula can also be divided in four climatic regions:

- The north-western region has a Csb type of climate (temperate with dry and warm summer), influenced by the Atlantic Ocean and very humid in the winter months, with conditions for fast vegetation growth but also for wildfire occurrence. It corresponds to most of the NW pyro-region and a small (western) part of the N;

- The region covering most of the Cantabria and the north-eastern region, as well as some mountainous areas in the east, has Cfa or Cfb climates (temperate without a dry season and hot or warm summer, respectively), with the low rainfall seasonality creating unfavourable conditions for wildfire occurrence and spread. It corresponds to most of the $\mathrm{N}$ pyro-region and a small (northern) part of the $\mathrm{E}$;

- Most of the E pyro-region has the steppe climate (BSh and BSk), with less available vegetation to burn than the other Iberian regions (del Barrio et al., 2010); 
- Finally, most of the southwest has the Csa type of climate (temperate with a dry and hot summer), which is less humid than NW in winter, implying that the vegetation is not very dense and grows slowly. It corresponds to most of the SW pyro-region, and small parts of the E pyro-region.

A visual inspection clearly suggests that the shape and size of clusters fit Iberia's climate types, i.e., that climate drives the fire regime in Iberia. However, this conclusion is not based on a quantitative assessment of the relationship between climate type and pyro-regions, and therefore a statistical significance cannot be ascribed to it.

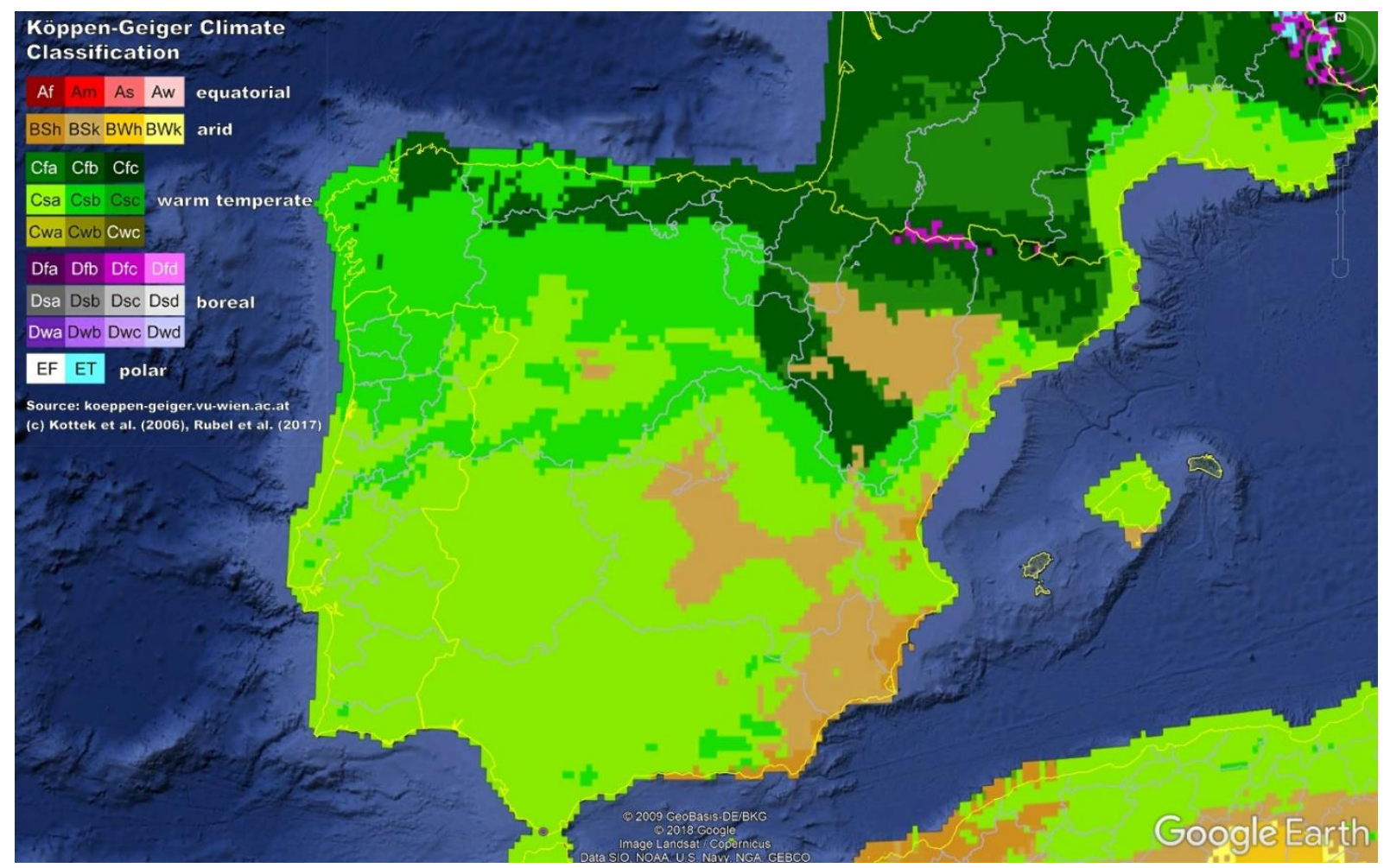

Figure 4: Köppen climate classification in the Iberian Peninsula (Kottek et al., 2006; Rubel et al., 2017).

\subsection{Fire Weather patterns}

The box-whisker plots of the fire weather indices in each month for the $1980-2015$ period (Figure 5) disclose, in general, a similar fire weather patterns in each pyro-region. BUI, which 
represents the fuel available for consumption, has a significant peak in summer (June to September, with the highest value in August), and significantly lower values in the other months. Extreme BUI values, however, are very distinct in each pyro-region, due to the combination of climate, climate variability and predominant type of vegetation. For example, the highest BUI in August is in the E (250), followed by the SW (190), NW (110) and N (70).

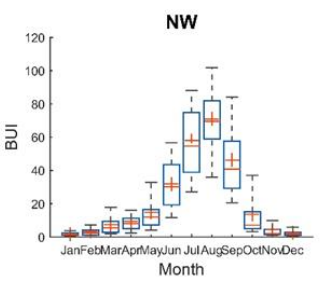

SW

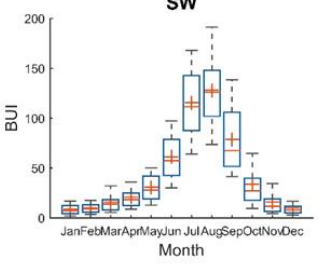

NW

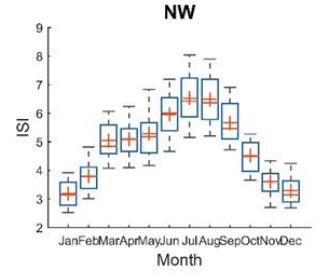

sw

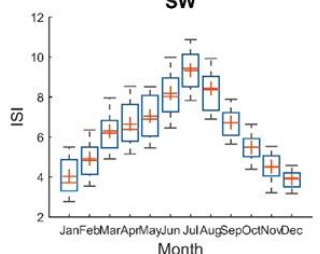

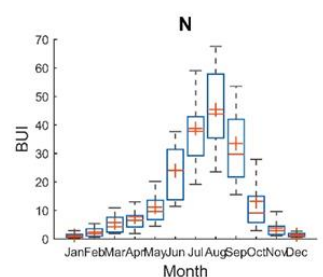

E

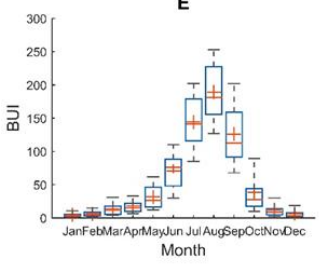

N

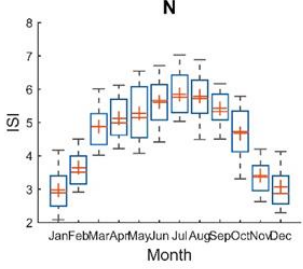

$E$

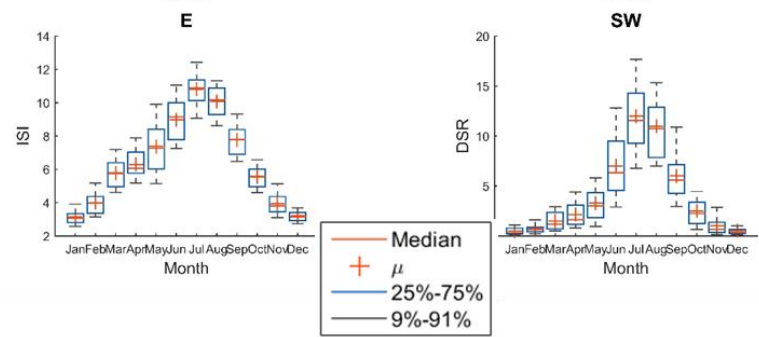

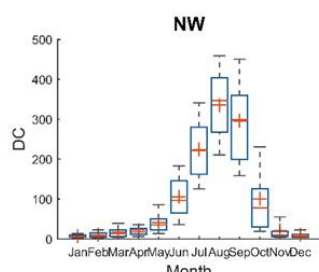

sw

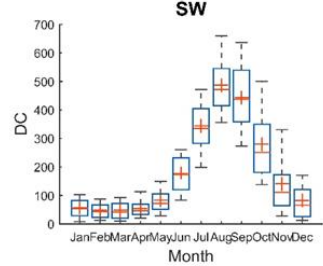

NW
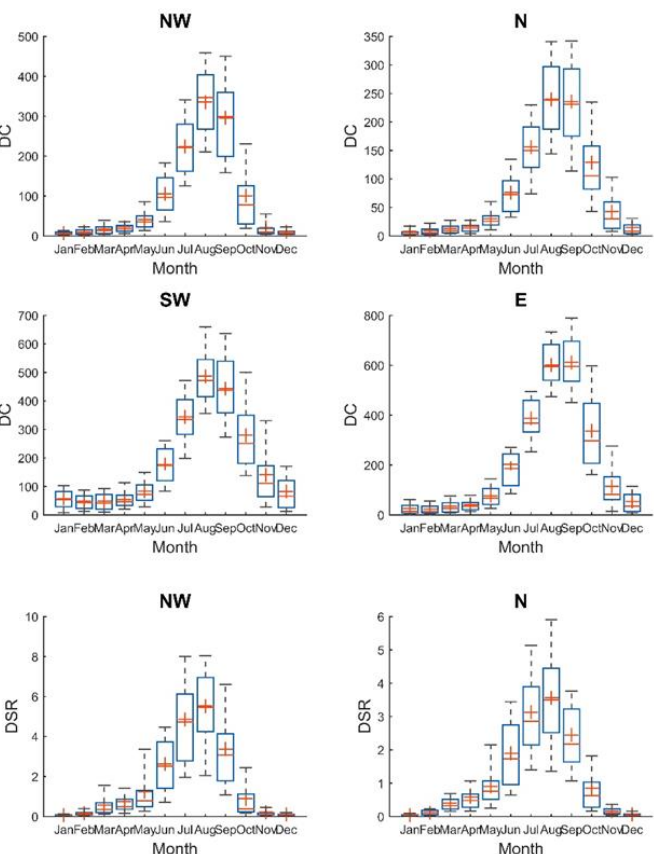

N

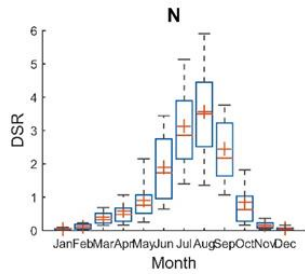

E

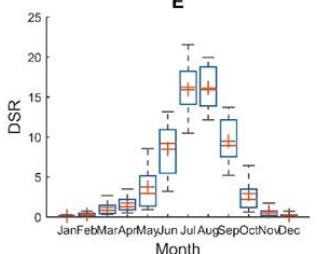

Figure 5: Box and whisker plots of monthly BUI (top left), DC (top right), ISI (bottom left) and DSR (bottom right), for the $1980-2015$ period. It is important to note the adoption of different vertical axis for a proper comparison of the seasonal pattern of the fire weather indices in each pyro-region.

The DC (indicating seasonal drought effects on forest fuels) has a seasonal pattern similar to that of BUI, strongly influenced by annual climate cycle and also by the type of vegetation. The highest peak of DC occurs in August, but the extremes are typically registered in September 
with the highest values in E ( 800), NW (500) and N (350). The exception is the SW pyroregion, where extreme DC occurs in August (650) and September (600). July and October have considerably high, but lower DC values.

The highest mean value of ISI (expected spread of fire, highly dependent on wind values) usually occurs in July, except for the NW pyro-region where it occurs in August. The ISI pattern in the E pyro-region has the highest seasonal variability, similar to the NBA seasonal pattern, with a peak in July and also a high value in August.

The seasonal pattern of DSR is a combination of the indexes presented before. The highest mean monthly value occurs in August in E (16), NW (6) and N (4), although the E pyro-region has the highest extreme in July (22). In the SW, however, the highest DSR mean value is in July (13).

Fire depends on weather, vegetation and ignition sources (Krebs et al., 2010). The N pyroregion is characterized by high concentration of vegetation but relatively low values of DSR and few ignitions (13\% of total), therefore leading to low levels of NBA. However, the number of ignitions increases with appropriate weather conditions, especially associated with southern winds, causing adiabatic heating of the air flow in the Cantabria mountainous area (Rodrigues et al., 2019).

In the NW pyro-region, there is also a high concentration of vegetation; nevertheless, there are more ignitions (56\% of total) and higher DSR in summer months. This leads to many small wildfires that can evolve into large wildfires under extreme fire weather conditions. The two other pyro-regions, SW and E, present higher values of DSR but low vegetation cover (there are even some steppe regions in parts of the E). Ignitions are not as common as in the NW pyroregion (24\% in SW and 7\% in E), but DSR is usually considerably much higher than in the $\mathrm{N}$ and NW pyro-regions. The relatively few ignitions have less probability of spreading into a 
large fire due to the type and density of the vegetation. However, weather conditions are the worse for firefighting and the most suitable for the occurrence of large/extreme wildfires.

In general, FWI indexes present a general similar seasonal pattern in all pyro-regions, with a peak in summer (centred in August) and considerably higher values from June to September, although with different values. The exception occurs in the E pyro-region, where the highest ISI mean value occurs in July, possibly explaining the different NBA seasonal patterns. Therefore, the NBA summer peak can be explained by the simultaneous fire weather peak in the pyro-regions. However, the NBA winter peak, even being small compared with the summer peak, is more difficult to explain only using summer fire weather, especially in the N and NW pyro-regions.

\subsection{Extreme Days}

Table 2 presents the monthly NBA in descending order, highlighting the months with higher NBA contributing to a cumulated fraction (CF) of $90 \%$ of the total NBA in each pyro-region for the 1980 - 2015 period. A link between burnt area and extreme days was found, showing that each pyro-region has a correspondent intra-annual extreme days pattern, with high correlation in the NW, SW and E pyro-regions (0.92 in NW and E, 0.94 in SW) but not in the $\mathrm{N}$ region $(0.46)$.

The winter peak of NBA in the N and NW pyro-regions can be justified by meteorological factors when using DC. Based on the Number of Extreme Days (NED), an analysis between the DC anomalies, for the 1980 - 2015 period, and the NBA in March, was performed for each pyro-region (Figure 6).

Table 2: Monthly NBA and cumulative fraction (CF) in each pyro-region for $1980-2015$ period. Months are sorted by descending order of NBA. Blue: months adding up to at least 50\%; green: remaining months adding up 
to at least $80 \%$; yellow: remaining months adding up to at least $90 \%$. Filled: warm season; Vertical lines: cold season.

\begin{tabular}{|c|c|c|c|c|c|c|c|c|c|c|c|}
\hline \multicolumn{3}{|c|}{$\mathbf{N}$} & \multicolumn{3}{|c|}{ NW } & \multicolumn{3}{|c|}{$E$} & \multicolumn{3}{|c|}{ SW } \\
\hline Month & NBA & CF & Month & NBA & CF & Month & NBA & CF & Month & NBA & CF \\
\hline 3 & 0.79 & 0.18 & 8 & 8.47 & 0.45 & 7 & 1.10 & 0.39 & 8 & 1.99 & 0.41 \\
\hline 9 & 0.72 & 0.35 & 9 & 3.53 & 0.64 & 8 & 0.72 & 0.65 & 7 & 1.38 & 0.69 \\
\hline 8 & 0.59 & 0.49 & 7 & 2.97 & 0.80 & 9 & 0.23 & 0.74 & 9 & 0.83 & 0.86 \\
\hline 2 & 0.56 & 0.62 & 3 & 0.96 & 0.86 & 6 & 0.23 & 0.82 & 6 & 0.24 & 0.91 \\
\hline 4 & 0.39 & 0.71 & 10 & 0.82 & 0.90 & 10 & 0.13 & 0.86 & 10 & 0.16 & 0.95 \\
\hline 12 & 0.33 & 0.78 & 6 & 0.60 & 0.93 & 4 & 0.10 & 0.90 & 3 & 0.08 & 0.96 \\
\hline 10 & 0.26 & 0.84 & 4 & 0.49 & 0.96 & 3 & 0.06 & 0.92 & 2 & 0.05 & 0.97 \\
\hline 1 & 0.24 & 0.90 & 2 & 0.27 & 0.97 & 12 & 0.06 & 0.94 & 5 & 0.04 & 0.98 \\
\hline 7 & 0.23 & 0.95 & 5 & 0.22 & 0.98 & 5 & 0.05 & 0.96 & 4 & 0.04 & 0.99 \\
\hline 5 & 0.10 & 0.97 & 11 & 0.13 & 0.99 & 2 & 0.05 & 0.98 & 11 & 0.02 & 0.99 \\
\hline 6 & 0.07 & 0.99 & 12 & 0.09 & 1.00 & 1 & 0.04 & 0.99 & 12 & 0.02 & 1.00 \\
\hline 11 & 0.06 & 1.00 & 1 & 0.07 & 1.00 & 11 & 0.02 & 1.00 & 1 & 0.01 & 1.00 \\
\hline
\end{tabular}
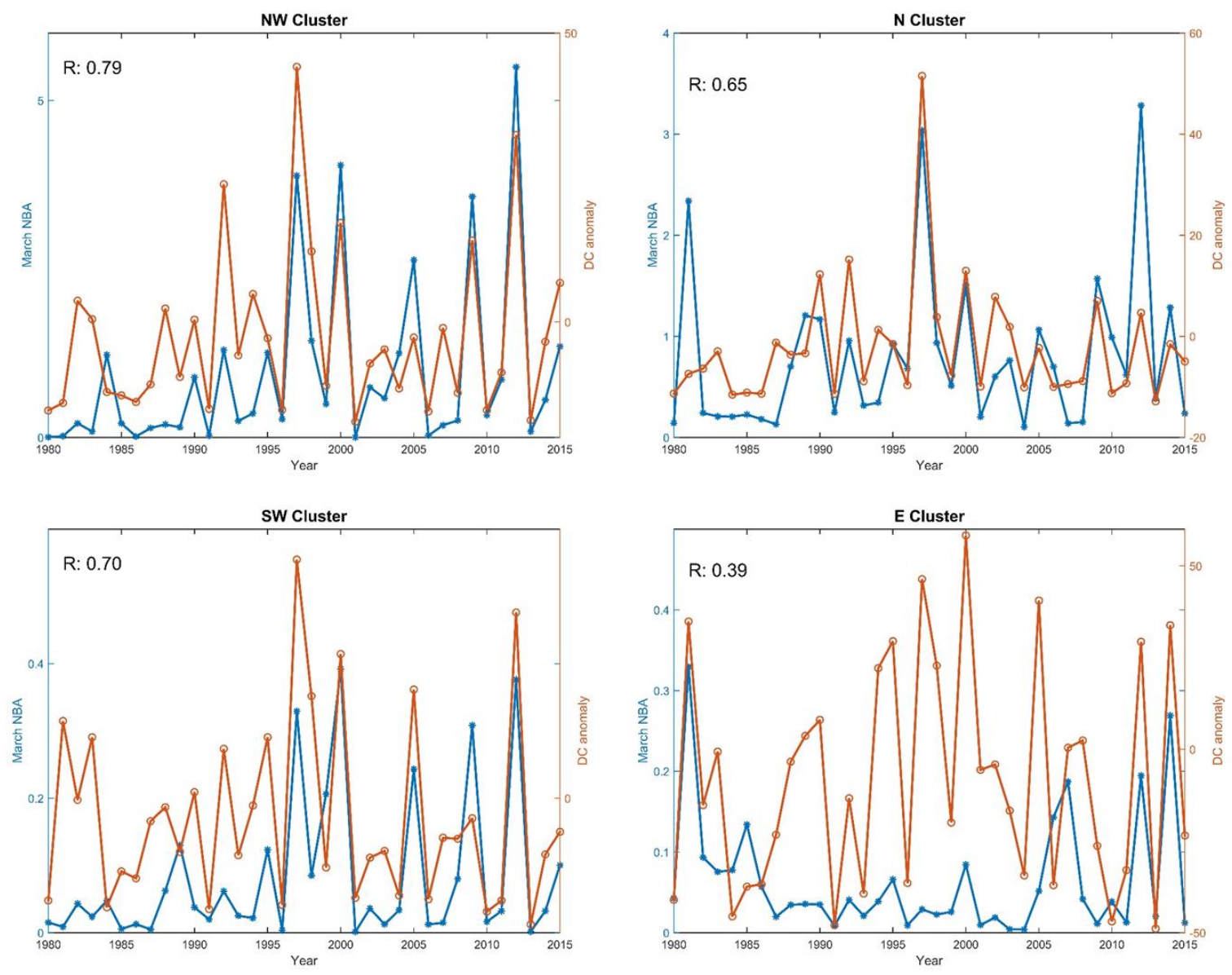

Figure 6: NBA (blue line) in March (in permillage) and DC anomaly (red line), for the 1980-2015 period, with correlation (R), for each pyro-region. 
In fact, the correlation between NBA in March and the DC anomaly is high in the NW and N pyro-regions, respectively 0.79 and 0.65 . In the NW pyro-region, the four years with the highest NBA in March (2012, 2000, 1997 and 2009) also present a significant positive DC anomaly. These are also the years with the highest NBA in the N pyro-region, except in 1981, where the DC anomaly is slightly negative; in this year there was a winter drought, but DC was smoothed by a rainy March. In the SW pyro region, despite the lower NBA in March, the correlation is also surprisingly high $(\mathrm{R}=0.70)$, and 3 of the 4 years with the highest NBA values also present strong positive DC anomalies. However, the correlation is much lower in the E pyro-region $(\mathrm{R}=0.39)$.

The high values of NBA in March can be explained by the combination of a lack of precipitation, revealed by positive anomalies of DC, with agricultural practices generating a large number of wildfires that can spread due to the type of vegetation (Jurdao et al., 2012; Dacamara et al., 2014; Trigo et al., 2016).

Box-whisker plots of monthly averages of NED were plotted together with monthly averages of NBA and number of fires, for each pyro-region (Figure 7). Large NED generally corresponds to the higher values of monthly NBA and number of fires, also when comparing the seasonal pattern in the SW and E pyro-region (Figure 5). The results show that the month with higher mean NED in the NW and N pyro-regions is August, but in the E and SW is July.

An analysis in each pyro-region indicates that:

- In general, the NW has the highest NED during summer months, but also presents extreme values of NED in March, agreeing well with the NBA and number of fires seasonal pattern in this pyro-region (Figure 6). This fact, together with the vegetation type and the high number of ignitions, can explain the higher values of the NBA in this pyro-region; 

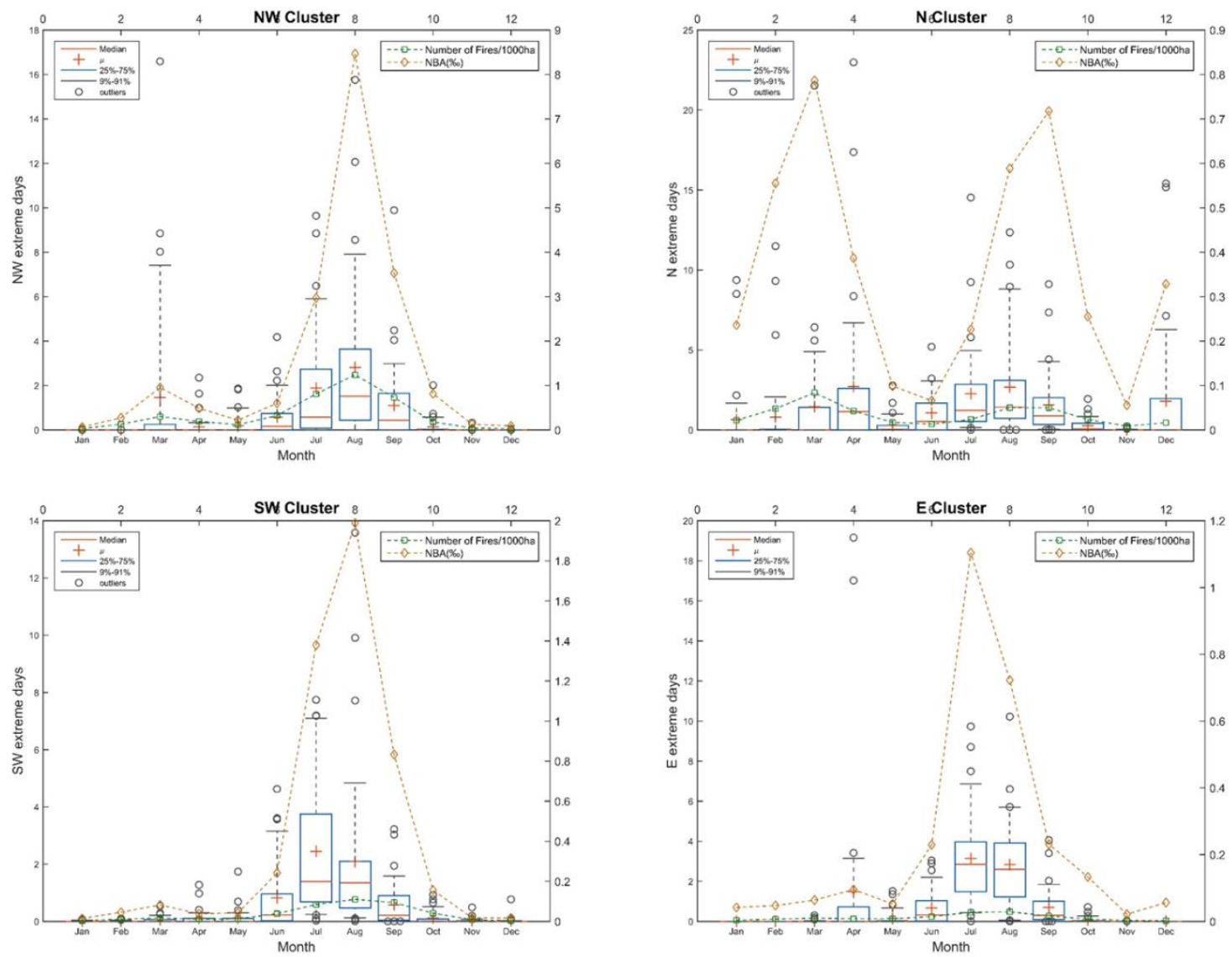

Figure 7: Box-whiskers plots of monthly number of extreme days (NED) in each pyro-region, monthly NBA (brown dashed line) and average fire density (green dashed line), both in permillage, for the 1980-2015 period. Outliers are represented in black circles.

- In the N region, the seasonal pattern of NED also agrees well with the NBA and number of fires, with one month of delay after in March and one month of anticipation in September. Further research is needed to explain this behaviour. The highest value of number of fires along with the also high value of NED in March helps understand the peak of the NBA in this month and not in April. This result can explain the difference between the pyro-regions $\mathrm{N}$ and NW in the warm season (especially in summer) and also explain the higher values of NBA in the cold season in this pyro-region;

- In the SW, the higher NED between June and September is clear, and these are the months with the higher number of fires and NBA; 
- Finally, in the E, July is the month with the highest mean value of NED and the highest NBA. August has, however, the highest extreme values of NED. A particular month is April, with a small peak of NED, that also agrees with the relatively higher values of NBA in this month, for the cold season. April has the two highest outliers of NED in this pyro-region (19).

\subsection{Extreme fire weather changes in last decades}

Given the link between climate variability/fire weather and NBA, we compare the monthly $95^{\text {th }}$ DSR (for July, August and September) and the $95^{\text {th }}$ DC (for March) percentiles for the two sub periods (1980 - 1997 and 1998 - 2015) to assess if the meteorological factors explain the NBA intra-annual variability and the administrative region change between pyro-regions (Figures 1, $3 \mathrm{a}$ and $3 \mathrm{~b}$ ). These months were chosen because they have the highest NBA in the SW, NW and E pyro-region. Analysing the results for those months, it is visible that March has small variations in DC, except in the Tagus valley, the extreme southeast and the Ebro valley, where there is a particularly strong variation in the transition with the Pyrenees Mountains. In July, most of Iberia has an increase of DSR, except in the southwest. August also presents an increase in almost all the Peninsula, with small exceptions in the extreme north and parts of the western edge. Finally, September has decreases of DSR in southwestern and northeastern Iberia with the remaining areas presenting an increase.

The obtained results for the analysed administrative regions (Figure 8) indicate that:

- In Bragança, extreme DC increased in March. This pattern is in accordance with the increase of the NBA in this province that changed from the SW to NW pyro-region. The increase of extreme DSR in August and September is also visible, in accordance with the increase of NBA in those months. However, the link between the increase of NBA 
in July and extreme DSR is not so clear, since most of province has a observed a decrease of extreme DSR;
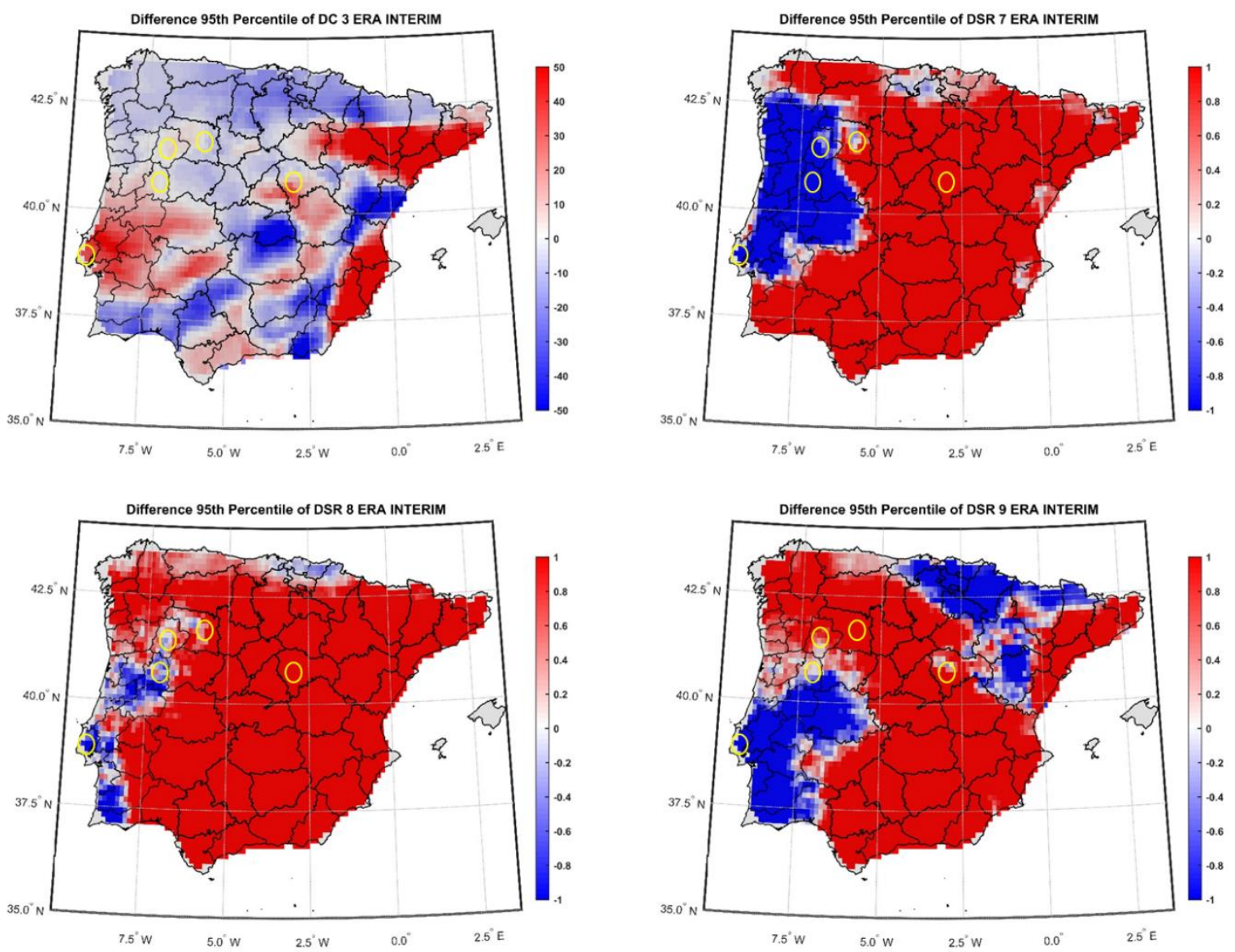

Figure 8: Differences of the $95^{\mathrm{h}}$ percentile of DC, between 1980 - 1997 and 1998 - 2015, for March (upper left); the same for DSR, for July (upper right), August (lower left) and September (lower right). Yellow circles indicate the 5 provinces that changed their pyro-region between $1980-1997$ and $1998-2015$.

- In Guarda, extreme DC also increased in March, consistent with the increase of NBA. The NBA increased in August and decreased in September and the DSR increased in some parts of the province but decreased in others. It is important to mention that the variations for the summer months are relatively smaller than in March, due to the relatively higher values. In July, the higher NBA is accompanied by a decrease of extreme DSR, contrary to what was expected; 
- In Lisboa, the extreme DC in March is higher in the last period, agreeing well with the increase in NBA. In July and August, the decreases in extreme DSR are also in line with the decrease in NBA, especially in August. However, the results are contradictory in September, with the decrease in DSR and an increase in NBA;

- In Zamora, the increase in NBA is associated with an increase (in some parts) of extreme DC. This relationship is also not completely clear for July and August, where lower NBA values are associated with a decrease in extreme DSR in some parts. In September, the DSR extreme values are higher in the last period;

- Finally, in Guadalajara the results agree with the link between the extreme weather and NBA, especially in July and August. Both extreme DSR and NBA increased in these months. In March, the difference of NBA is almost null and the DC differences are not clear, with increase in some parts and decrease in others. In September, the results are dubious due to an increase of extreme DSR in a larger area and a decrease in a small area.

Additionally, a change in the correlation between the NBA in March and the DC anomaly is visible after 1990 in the N, NW and SW pyro-regions. This correlation is much higher in the last period ( 1991 - 2015), comparing with 1980 - 1990 for the $\mathrm{N}(\mathrm{R}=0.72$ with $\mathrm{R}=0.31$, respectively), $\mathrm{NW}(\mathrm{R}=0.85$ with $\mathrm{R}=0.13)$ and $\mathrm{SW}(\mathrm{R}=0.79$ with $\mathrm{R}=0.11)$ pyro-regions. This is consistent with a change from a fuel-limited to a drought-driven fire regime proposed by other authors (Pausas and Fernández-Muñoz, 2012).

The results suggest that meteorological factors can explain the changes of NBA intra-annual variability and pyro-region composition in most provinces. However, it is also important to note that results are not completely clear in some months, possibly highlighting that NBA does not only depends on fire weather, but also on other local human and natural factors, 
such as type of vegetation, population density and activities, agricultural practices and land use.

\subsection{Large fires}

The study of the fire weather in the location and during the occurrence of large fires may help to complement the understanding of extreme weather on extreme wildfires. The largest wildfire in the Iberian Peninsula occurred in the municipality of Oliveira do Hospital (central Portugal, NW pyro-region) on October 15 2017, and burned 64321 ha (EFFIS, 2018). The DSR in October 15 was 58, which is nearly 4 times extreme day limit in NW (Figure 9, top left panel). This extreme value is the highest in the study period $(1979-2017)$ and considerably higher (42\%) than the second highest value (41, in August 2015). The weather on that day was influenced by unusual synoptic conditions, with the approximation of the Hurricane Ophelia to Iberia, with strong and very dry southern winds from North Africa. The exceptional fire weather conditions were combined with a severe drought that started earlier in the year, which led to vegetation dryness.

The second case study is the wildfire at the Arouca municipality (northern Portugal, NW pyroregion), from August 7 to 17 2016, which burned a total of 26593 ha (EFFIS, 2018). It was the largest wildfire in the Iberian Peninsula in that year. Values of DSR in the nearest point of the wildfire ignition were extreme during the days the wildfire remained active, reaching a maximum of 39.6 (Figure 9, top right). This was the second highest DSR in the NW pyro-region during the study period. The highest value of the DSR in this region was also registered in October 152017 (50); some likely reasons why it did not lead to wildfires are the possible lack of ignitions and the burning of the vegetation in the previous year. 

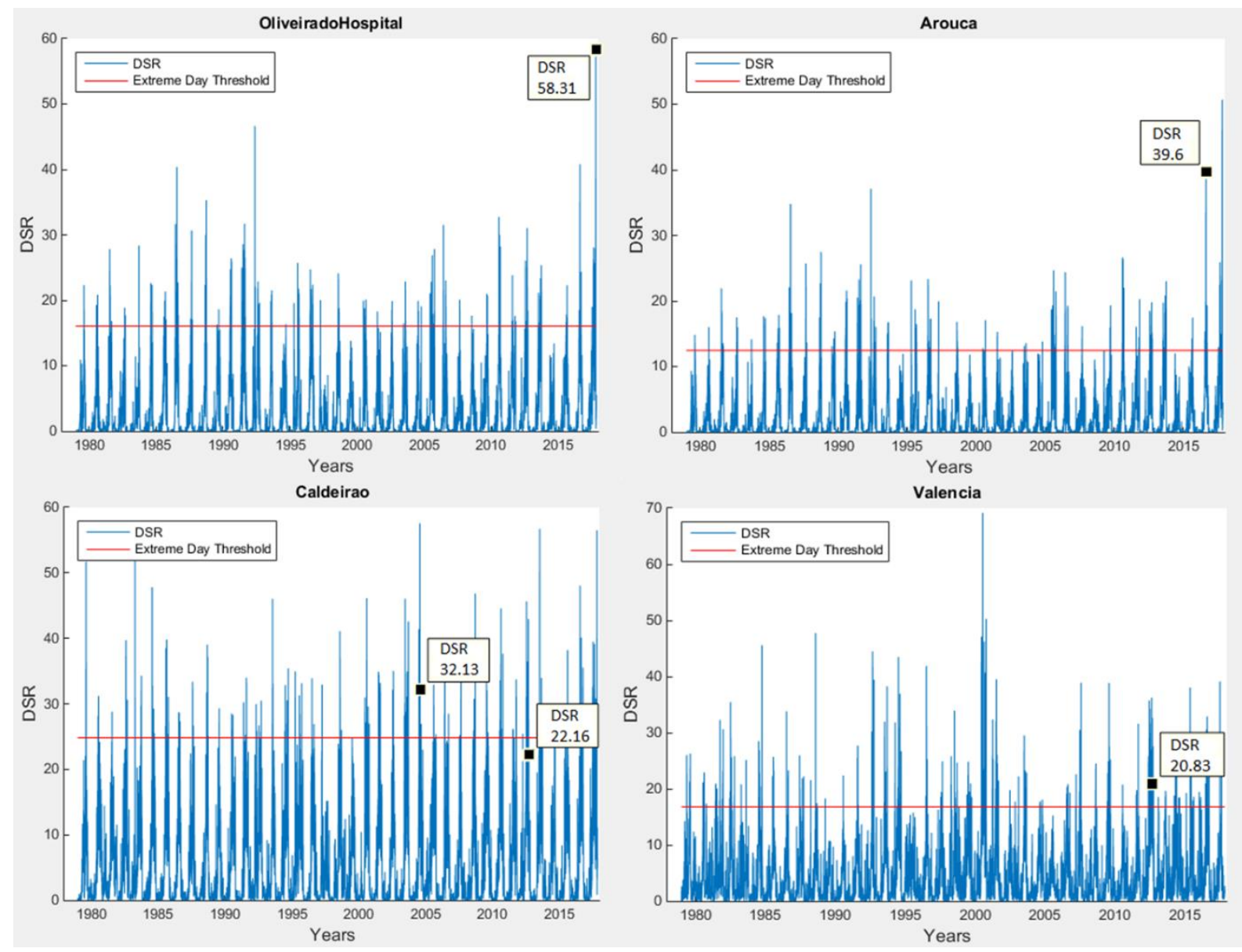

Figure 9: Historical DSR values (blue line) for Oliveira do Hospital (top left); for Arouca (top right); for Serra do Caldeirão (bottom left) and for Valencia (bottom right). Also shown is the extreme day threshold for each pyroregion, for 1980-2014 (red line); boxes show the DSR occurred in the studied large fires.

Another case study is the Serra do Caldeirão (Algarve, Portugal, SW pyro-region), a place where two large wildfires occurred. The first ran from July 26 to 30, 2004, burning 27784 ha and the second last from July 18 to 21, 2012, affecting 26442 ha (EFFIS, 2018). DSR values during the days the wildfire remained active were not extreme in the second fire (Figure 9, bottom left). This fact can be explained by the climate of this region, which is prone to higher DSR values in the summer and, therefore the threshold for extreme days is also higher than the two previous case studies in the NW pyro-region. In addition, the number of ignitions in this 
pyro-region is much lower than in the NW. Nevertheless, both wildfires burned in severe DSR conditions (maximum of 32), higher than the extreme day threshold (25).

Finally, the fourth case is the wildfire in Dos Aguas (Valencia, Spain, E pyro-region), starting on June 28, 2012, and continuing to burn in the first days of July, affecting 34424 ha (EFFIS, 2018). This wildfire started in an extreme day (DSR was 20 and the threshold for extreme day is 18) and the conditions for fire spread deteriorated considerably in the second day, when DSR reached a maximum of 30 (Figure 9, bottom right). In the last day of June of 2012, DSR dropped to 13 and the wildfire started to be extinguished. Comparing to other extreme days, the highest DSR value (70) was notably larger than the one observed during this wildfire. This region has a higher DSR average than that of the previous case studies, and has also the driest conditions in the Iberian Peninsula, an earlier fire peak in the summer (in July), less vegetation cover and lower ignitions. Fire prone conditions in the region are usually a combination of drought (more common than the other fire pyro-regions) and a cyclonic or south-eastern extreme heat episode during summer (Rodrigues et al., 2019).

\section{Conclusions}

Fire regime and fire weather were characterized in the Iberian Peninsula for present-day climate conditions (1980 - 2015). Results were compared with the findings of previous studies (Sousa et al., 2015; Trigo et al., 2016) to detect potential changes. The pyro-regions developed in the previous studies for 1980-2005 remained essentially unchanged for the prolonged 1980 - 2015 period, highlighting the different fire regimes in the Iberian Peninsula. However, when analysing changes between 1980 - 1997 to 1998 - 2015, five border administrative divisions moved from the SW to the NW pyro-region, while another moved from the SW to the E, due to changes in the NBA seasonal pattern. 
FWI indexes presented, in general, a similar inter annual pattern in the pyro-regions, with a main peak in summer, centred in August, although with different values; in the E region, ISI showed a peak in July instead of August, possibly explaining the different NBA seasonal patterns. Climate types were shown to be good rough estimators of the pyro-region size, location, and characteristics in the Iberian Peninsula, which suggests that changes in the types of climate, as those projected by Rubel and Kottek (2010), may lead to lead to changes in the fire regime of the pyro-regions.

DSR and DC could explain the NBA modifications in most of months, but in some cases the link was not completely clear, highlighting that the relationship between NBA and meteorological conditions may need to be complemented with the effects of other local landscape or human driving factors. In particular, the winter/spring peak of NBA in the N and NW pyro-regions could not be justified with DSR alone, but could be explained by a combination of drought (through DC) and agricultural practices, generating a large number of wildfires that can spread due the type of vegetation and to a lack of precipitation, as suggested. An analysis of the intra-annual pattern of extreme fire weather days (days with DSR > P95 in summer or DC > P95 in winter-spring) in the 4 pyro-regions allowed for an explanation of the differences between the N and NW pyro-regions in summer, and of the higher values of NBA in the spring/winter season, especially in March. The NED seasonal pattern agreed well with the patterns of NBA and number of fires in the NW region, and also in the N region with small displacements. Large NED generally corresponded to the higher values of NBA and number of fires, also when comparing the seasonal pattern in the SW and E.

The 2 very large wildfires which occurred in the NW pyro-region were clearly driven by days with extreme DSR, in some cases the highest occurred in the observed period. However, this link between large fires and extreme DSR was not so evident in the SW and even less in the E pyro-region. 
These results highlight and help to cement the link between climate and fire regime and can therefore help to predict the impacts of climate change in Iberia. However, it will remain very difficult to assess climate change impacts in fire regimes because they also depend on human (ignitions, land cover changes) and natural (vegetation structure) drivers, which are not always considered in climate change studies (Pereira et al., 2013; Parente et al., 2016). A fire regime model which can relate all these variables (instead of only using climate) and a detailed analysis of the area burned during extreme days could bring significant progress in future works.

\section{Acknowledgments}

T. Calheiros and J.P. Nunes were supported by research grants from the Fundação para a Ciência e a Tecnologia (PD/BD/128173/2016 and IF/00586/2015).

The study was also supported by: i) project FIREXTR - Prevent and prepare society for extreme fire events: the challenge of seeing the "forest" and not just the "trees", co-financed by the European Regional Development Fund (ERDF) through the COMPETE 2020 Operational Program Competitiveness and Internationalization (POCI Ref: 16702) and national funds by FCT-Portuguese Foundation for Science and Technology (FCT Ref: PTDC/ATPGEO/0462/2014); ii) Project Interact - Integrative Research in Environment, Agro-Chain and Technology, NORTE-01-0145-FEDER-000017, research line BEST, cofunded by FEDER/NORTE 2020; and, iii) National Funds by FCT - Portuguese Foundation for Science and Technology, under the projects UID/AGR/04033/2019 and UID/BIA/00329/2019. 


\section{REFERENCES}

Abatzoglou, J. T. and Williams, A. P. (2016) 'Impact of anthropogenic climate change on wildfire across western US forests', PNAS. doi: 10.1073/pnas.1607171113.

Alduchov, O. A. and Eskridge, R. E. (1996) 'Improved Magnus Form Approximation of Saturation Vapor Pressure', Journal of Applied Meteorology, pp. 601-609. doi: 10.1175/1520-0450(1996)035<0601:IMFAOS>2.0.CO;2.

Amatulli, G., Camia, A. and San-miguel-ayanz, J. (2013) 'Estimating future burned areas under changing climate in the EU-Mediterranean countries', Science of the Total Environment, The. Elsevier B.V., 450-451, pp. 209-222. doi:

10.1016/j.scitotenv.2013.02.014.

Amraoui, M., Pereira, M. G., Dacamara, C. and Calado, T (2015) 'Atmospheric conditions associated with extreme fire activity in the Western Mediterranean region', Science of the Total Environment. Elsevier B.V., 524-525, pp. 32-39. doi: 10.1016/j.scitotenv.2015.04.032. Area de Defensa Contra Incendios Forestales (2018) 'D.G. de Medio Natural y Política Forestal', p. 2

Barrera, F. de la, Barraza, F., Favier, P., Ruiz, V. and Quense, J. (2018) 'Mega fires in Chile 2017 : Monitoring multiscale environmental impacts of burned ecosystems', Science of the Total Environment. Elsevier B.V., 637-638, pp. 1526-1536. doi: 10.1016/j.scitotenv.2018.05.119.

del Barrio, G., Puigdefabregas, J., Sanjuan, M., Stellmes, M. and Ruiz, A. (2010) 'Assessment and monitoring of land condition in the Iberian Peninsula , 1989-2000', Remote Sensing of Environment. Elsevier Inc., 114(8), pp. 1817-1832. doi: 10.1016/j.rse.2010.03.009.

Batllori, E., Parisien, M., Krawchuk, M. and Moritz, M. (2013) 'Climate change-induced shifts in fire for Mediterranean ecosystems', Global Ecology and Biogeography, 22(10), pp. 
1118-1129. doi: 10.1111/geb.12065.

Bedia, J., Herrera, S. and Guti, J. M. (2012) 'Sensitivity of fire weather index to different reanalysis products in the Iberian Peninsula', Natural Hazards and Earth System Sciences, pp. 699-708. doi: 10.5194/nhess-12-699-2012.

Bedia, J., Herrera, S. and Gutiérrez, J. M. (2014) 'Assessing the predictability of fire occurrence and area burned across phytoclimatic regions in Spain', Natural Hazards and Earth System Science, 14(1), pp. 53-66. doi: 10.5194/nhess-14-53-2014.

Berrisford, P. Dee, D., Fielding, K., Fuentes, M., Kallberg, P., Kobayashi, S. and Uppala, S. (2009) 'The ERA-Interim Archive', ERA report series, 1(1), pp. 1-16. Available at: http://www.ecmwf.int/publications/library/do/references/list/782009.

Camara, C. C. da, Pereira, M., Calado, T. and Calheiros, T. (2014) 'Impacts of climate change on the fire regime in Portugal', in Advances in forest fire research. Imprensa da Universidade de Coimbra, pp. 1193-1206. doi: 10.14195/978-989-26-0884-6_130.

Cardil, A. and Molina, D. M. (2015) 'An International Factors Causing Victims of Wildland Fires in Spain ( 1980 - 2010 ) Factors Causing Victims of Wildland Fires in Spain', Human and Ecological Risk Assessment, 7039. doi: 10.1080/10807039.2013.871995.

Dacamara, C. C., Trigo, R. M. and Nascimento, M. L. (2014) 'Characterizing the secondary peak of Iberian fires in March', in Advances in Forest Fire Research. doi: :http://dx.doi.org/10.14195/978-989-26-0884-6_184.

Dee, D. P., Uppala, S. M., Simmons, A. J., Berrisford, P., Poli, P., Kobayashi, S., Andrae, U., Balmaseda, M. A., Balsamo, G., Bauer, P., Bechtold, P., Beljaars, A. C.M., van de Berg, L., Bidlot, J., Bormann, N., Delsol, C., Dragani, R., Fuentes, M., Geer, A. J., Haimberger, L., Healy, S. B., Hersbach, H., Hólm, E. V., Isaksen, L., Kållberg, P., Köhler, M., Matricardi, M., Mcnally, A. P., Monge-Sanz, B. M., Morcrette, J. J., Park, B. K., Peubey, C., de Rosnay, P., 
Tavolato, C., Thépaut, J. N. and Vitart, F. (2011) 'The ERA-Interim reanalysis:

Configuration and performance of the data assimilation system', Quarterly Journal of the Royal Meteorological Society, 137(656), pp. 553-597. doi: 10.1002/qj.828.

Doerr, S. H. and Santín, C. (2016) 'Global trends in wildfire and its impacts: perceptions versus realities in a changing world', Philosophical Transactions of the Royal Society B: Biological Sciences, 371(1696), p. 20150345. doi: 10.1098/rstb.2015.0345.

Duane, A. and Brotons, L. (2018) 'Synoptic weather conditions and changing fire regimes in a Mediterranean environment', Agricultural and Forest Meteorology. Elsevier, 253254(January), pp. 190-202. doi: 10.1016/j.agrformet.2018.02.014.

EFFIS (2018) 'EFFIS - Current Situation.pdf'. Available at: http://effis.jrc.ec.europa.eu/static/effis_current_situation/public/index.html.

Flannigan, M., Cantin, A., de Groot, W., Wotton, M., Newbery, A. and Gowman, L. (2013) 'Global wildland fire season severity in the 21st century', Forest Ecology and Management, 294(APRIL), pp. 54-61. doi: 10.1016/j.foreco.2012.10.022.

Flannigan, M. D., Wotton, B. M., Marshall, G. A., de Groot, W. J., Johnston, J., Jurko, N. and Cantin, A. S. (2016) 'Fuel moisture sensitivity to temperature and precipitation: climate change implications', Climatic Change, 134(1-2), pp. 59-71. doi: 10.1007/s10584-015-15210.

García-Ortega, E., Trobajo, M. T., López, L., Sánchez, J. L., Lasaponara, R. and Ghermandi, L. (2011) 'Synoptic patterns associated with wildfires caused by lightning in Castile and Leon , Spain', Natural hazards and earth system sciences, (March). doi: 10.5194/nhess-11-8512011.

Gill, A. M. and Allan, G. (2008) 'Large fires, fire effects and the fire-regime concept', International Journal of Wildland Fire, 17(6), pp. 688-695. doi: 10.1071/WF07145. 
de Groot, W. J.(1987) 'Interpreting the Canadian Forest Fire Weather Index (FWI) System', Fourth Central Regional Fire Weather Committee Scientific and Technical Seminar,

Proceeding, pp. 3-14. Available at:

http://scholar.google.com/scholar?hl=en\&btnG=Search\&q=intitle:Interpreting+the+canadian+ forest+fire+weather+index+(FWI)+system\#0.

Hernandez, C., Drobinski, P. and Turquety, S. (2015) 'How much does weather control fire size and intensity in the Mediterranean region?', Annales Geophysicae, 33(7), pp. 931-939. doi: 10.5194/angeo-33-931-2015.

Hoinka, K. P. A., Carvalho, A. B. and Miranda, A. I. B. (2009) 'Regional-scale weather patterns and wildland fires in central Portugal', International Journal of Wildland Fire, pp. $36-49$.

Instituto da Conservação da Natureza e das Florestas (2018) 'Lista de incêndios florestais'. Available at: http://www2.icnf.pt/portal/florestas/dfci/inc/estat-sgif\#tot.

Jimenez-Ruano, A., Rodrigues, M., Jolly, W. M. and de la Riva, J. (2018) 'The role of shortterm weather conditions in temporal dynamics of fire regime features in mainland Spain', Journal of Environmental Management. Elsevier, In press(September), pp. 1-12. doi: 10.1016/j.jenvman.2018.09.107.

Jiménez-Ruano, A., Rodrigues Mimbrero, M. and de la Riva Fernández, J. (2017) 'Exploring spatial-temporal dynamics of fire regime features in mainland Spain', Natural Hazards and Earth System Sciences, 17(10), pp. 1697-1711. doi: 10.5194/nhess-17-1697-2017.

Jurdao, S., Chuvieco, E. and Arevalillo, J. M. (2012) 'Modelling fire ignition probability from satellite estimates of live fuel moisture content', Fire Ecology Volume, 8(1), pp. 77-97. doi: 10.4996/fireecology.0801077.

Kanevski, M. and Pereira, M. G. (2017) 'Local fractality: The case of forest fires in Portugal', 
Physica A. Elsevier B.V., 479, pp. 400-410. doi: 10.1016/j.physa.2017.02.086.

Kottek, M., Grieser, J., Beck, C., Rudolf, B. and Rubel, F. (2006) 'World Map of the KöppenGeiger climate classification updated', Meteorologische Zeitschrift, 15(3), pp. 259-263. doi: 10.1127/0941-2948/2006/0130.

Krebs, P., Pezzatti, G. B., Mazzoleni, S., Talbot, L. M. and Conedera, M. (2010) 'Fire regime : history and definition of a key concept in disturbance ecology', Theory Biosci., pp. 53-69. doi: 10.1007/s12064-010-0082-z.

Leuenberger, M., Parente, J. and Tonini, M. (2018) 'Wildfire susceptibility mapping:

Deterministic vs. stochastic approaches', Environmental Modelling \& Software, 101, pp. 194203. doi: 10.1016/j.envsoft.2017.12.019.

Li, C., Hans, H., Barclay, H., Liu, J., Carlson, G. and Campbell, D. (2008) 'Comparison of spatially explicit forest landscape fire disturbance models', Forest Ecology and Management, 254(3), pp. 499-510. doi: 10.1016/j.foreco.2007.07.022.

Liu, Z., Liu, Y., Wang, S., Yang, X., Wang, L., Baig, M. H. A., Chi, W. and Wang, Z. (2018) 'Evaluation of spatial and temporal performances of ERA-interim precipitation and temperature in Mainland China', Journal of Climate, 31(11), pp. 4347-4365. doi: 10.1175/JCLI-D-17-0212.1.

Molina-Terrén, D. M., Xanthopoulos, G., Diakakis, M. and Ribeiro, L. M. (2019) ‘Analysis of forest fire fatalities in Southern Europe : Spain, Portugal, Greece and Sardinia ( Italy )', International Journal of Wildland Fire, (January). doi: 10.1071/WF18004.

Parente, J., Pereira, M. G., Amraoui, M. and Fischer, E. M. (2018) 'Heat waves in Portugal: Current regime, changes in future climate and impacts on extreme wildfires', Science of the Total Environment. Elsevier B.V., 631-632, pp. 534-549. doi: 10.1016/j.scitotenv.2018.03.044. 
Parente, J., Pereira, M. G., Amraoui, M. and Tedim, F. (2018) 'Negligent and intentional fires in Portugal: Spatial distribution characterization', Science of the Total Environment. Elsevier B.V., 624, pp. 424-437. doi: 10.1016/j.scitotenv.2017.12.013.

Parente, J., Amraouia, M., Menezes, I. and Pereira, M.G. (2019) 'Drought in Portugal: Current regime, comparison of indices and impacts on extreme wildfires', Science of The Total Environment, 685, pp. 150-173. doi: 10.1016/j.scitotenv.2019.05.298.

Parente, J. and Pereira, M. G. (2016) 'Structural fire risk : The case of Portugal', Science of the Total Environment, 573, pp. 883-893. doi: 10.1016/j.scitotenv.2016.08.164.

Parente, J., Pereira, M. G. and Tonini, M. (2016) 'Space-time clustering analysis of wildfires: The influence of dataset characteristics, fire prevention policy decisions, weather and climate', Science of The Total Environment. Elsevier B.V., 559, pp. 151-165. doi: 10.1016/j.scitotenv.2016.03.129.

Parks, S. A., Miller, C., Abatzoglou, J. T., Holsinger, L. M., Parisien, M. and Dobrowski, S. Z. (2016) 'How will climate change affect wildland fire severity in the western US?', Environmental Research Letters. IOP Publishing, 11(3), p. 035002. doi: 10.1088/17489326/11/3/035002.

Pereira, M., Calado, T.J., DaCamara, C.C. and Calheiros, T. (2013) 'Effects of regional climate change on rural fires in Portugal', Climate Research, 57(3), pp. 187-200. doi: $10.3354 / \mathrm{cr} 01176$.

Pereira, M. G., Trigo, R. M., da Camara, C. C., Pereira, J. M. C. and Leite, S. M. (2005) 'Synoptic patterns associated with large summer forest fires in Portugal', Agricultural and Forest Meteorology, 129(1-2), pp. 11-25. doi: 10.1016/j.agrformet.2004.12.007.

Pereira, M. G., Malamud, B. D., Trigo, R. M. and Alves, P. I.. (2011) 'The history and characteristics of the 1980 - 2005 Portuguese rural fire database', Natural Hazards and Earth 
System Sciences, (Table 1), pp. 3343-3358. doi: 10.5194/nhess-11-3343-2011.

Pereira, M. G., Caramelo, L., Orozco, C. V., Costa, R. and Tonini, M. (2015) 'Space-time clustering analysis performance of an aggregated dataset: The case of wildfires in Portugal', Environmental Modelling \& Software, 72, pp. 239-249. doi: 10.1016/j.envsoft.2015.05.016.

Pérez-Sánchez, J., Senent-Aparicio, J., Díaz-Palmero, J. M. and Cabezas-Cerezo, J. D. (2017) 'A comparative study of fire weather indices in a semiarid south-eastern Europe region. Case of study: Murcia (Spain)', Science of the Total Environment. Elsevier B.V., 590-591, pp. 761-774. doi: 10.1016/j.scitotenv.2017.03.040.

Rasilla, D. F., García-Codron, J. C., Carracedo, V. and Diego, C. (2010) 'Circulation patterns, wildfire risk and wildfire occurrence at continental Spain', Physics and Chemistry of the Earth. Elsevier Ltd, 35(9-12), pp. 553-560. doi: 10.1016/j.pce.2009.09.003.

Rodrigues, M., Jiménez-Ruano, A., Peña-Angulo, D. and de la Riva, J. (2018) ‘A comprehensive spatial-temporal analysis of driving factors of human-caused wildfires in Spain using Geographically Weighted Logistic Regression', Journal of Environmental Management. Elsevier, 225(August), pp. 177-192. doi: 10.1016/j.jenvman.2018.07.098.

Rodrigues, M., González-Hidalgo, J. C., Peña-Angulo, D. and Jiménez-Ruano, A. (2019) 'Identifying wildfire-prone atmospheric circulation weather types on mainland Spain', Agricultural and Forest Meteorology. Elsevier, 264(October 2018), pp. 92-103. doi: 10.1016/j.agrformet.2018.10.005.

Rubel, F., Brugger, K., Haslinger, K. and Auer, I. (2017) 'The climate of the European Alps: Shift of very high resolution Köppen-Geiger climate zones 1800-2100', Meteorologische Zeitschrift, 26(2), pp. 115-125. doi: 10.1127/metz/2016/0816.

Rubel, F. and Kottek, M. (2010) 'Observed and projected climate shifts 1901 - 2100 depicted by world maps of the Koppen-Geiger climate classification World Map of Köppen - Geiger 
Climate Classification', Meteorologische Zeitschrift, 19(2), pp. 135-141. doi: 10.1127/09412948/2010/0430.

Russo, A., Gouveia, C. M., Páscoa, P., DaCamara, C. C., Sousa, P. M. and Trigo, R. M. (2017) 'Assessing the role of drought events on wildfires in the Iberian Peninsula', Agricultural and Forest Meteorology. Elsevier B.V., 237-238, pp. 50-59. doi: 10.1016/j.agrformet.2017.01.021.

San-miguel-ayanz, J., Durrant, T., Boca, R., Libertá, G., Branco, A., Rigo, D., Ferrari, D., Maianti, P., Vivancos, T. A., Costa, H., Lana, F., Loffler, P., Nujiten, D., Ahlgren, A. C. and Leray, T. (2018) Forest Fires in Europe, Middle East and North Africa 2017. doi: $10.2760 / 663443$.

Silva, J. M. N., Moreno, M. V., Page, Y. L., Oom, D., Bistinas, I. and Pereira, J. M. C. (2019) 'Spatiotemporal trends of area burnt in the Iberian Peninsula , 1975-2013', Regional Environmental Change. Regional Environmental Change, pp. 515-527.

Sousa, Pedro M., Trigo, R. M., Pereira, M. G., Bedia, J. and Gutiérrez, J. M. (2015) 'Different approaches to model future burnt area in the Iberian Peninsula', Agricultural and Forest Meteorology. Elsevier B.V., 202, pp. 11-25. doi: 10.1016/j.agrformet.2014.11.018.

Telesca, L. and Pereira, M. G. (2010) 'Time-clustering investigation of fire temporal fluctuations in Portugal', Natural hazards and earth system sciences, (April 2010). doi: 10.5194/nhess-10-661-2010.

Tonini, M., Pereira, M. G., Parente, J. and Orozco, C. V. (2016) 'Evolution of forest fires in Portugal : from spatio-temporal point events to smoothed density maps', Natural Hazards. Springer Netherlands, 85(3), pp. 1489-1510. doi: 10.1007/s11069-016-2637-x.

Trigo, R. M., Pereira, J. M. C., Pereira, M. G., Mota, B., Calado, T. J., Dacamara, C. C. and Santo, F. E. (2006) 'Atmospheric conditions associated with the exceptional fire season of 
2003 in Portugal', International Journal of Climatology, 26(13), pp. 1741-1757. doi: 10.1002/joc.1333.

Trigo, R. M., Sousa, P. M., Pereira, M. G., Rasilla, D. and Gouveia, C. M. (2016) 'Modelling wildfire activity in Iberia with different atmospheric circulation weather types', International Journal of Climatology, 36(7), pp. 2761-2778. doi: 10.1002/joc.3749.

Tsinko, Y., Bakhshaii, A., Johnson, E. A. and Martin, Y. E. (2018) 'Agricultural and Forest Meteorology Comparisons of fire weather indices using Canadian raw and homogenized weather data', Agricultural and Forest Meteorology. Elsevier, 262(December 2017), pp. 110119. doi: 10.1016/j.agrformet.2018.07.005.

Turco, M., Llasat, M. C., von Hardenberg, J. and Provenzale, A. (2014) 'Climate change impacts on wildfires in a Mediterranean environment', Climatic Change, 125(3-4), pp. 369380. doi: $10.1007 / \mathrm{s} 10584-014-1183-3$.

Vanesa Moreno, M. and Chuvieco, E. (2013) 'Characterising fire regimes in Spain from fire statistics', International Journal of Wildland Fire, 22(3), pp. 296-305. doi: 10.1071/WF12061.

Venevsky, S., Page, Y. Le and Wu, C. (2018) 'Analysis fire patterns and drivers with a global SEVER-FIRE model incorporated into Dynamic Global Vegetation Model and satellite and on-ground observations .', Geosci. Model Dev. Discuss., (August).

Van Wagner, C. . and Pickett, T. L. (1975) 'Equations and fortran IV program for the 1976 metric version of the forest fire weather index'.

Van Wagner, C. E. (1987) 'Development and structure of the Canadian Forest Fire Weather Index System', Department of the Environment, Canadian Forestry Service. doi: Acessed in: https://cfs.nrcan.gc.ca/pubwarehouse/pdfs/19927.pdf

Van Wagner, C. E. and Pickett, T. L. (1985) 'Equations and FORTRAN program for the 
Canadian Forest Fire Weather Index System', Canadian Forest Service. Forestry Technical Report, p. 33. doi: citeulike-article-id:14026112.

Wotton, B. M. (2009) 'Interpreting and using outputs from the Canadian Forest Fire Danger Rating System in research applications', Environmental and Ecological Statistics, 16(2), pp. 107-131. doi: 10.1007/s10651-007-0084-2. 